\title{
Buoyancy and Dissolution of the Floating Crust Layer in Tank 241-SY-101 During Transfer and Back-Dilution
}

CW Stewart

SD Rassat

JH Sukamto

JM Cuta

November 1999

Prepared for

the U.S. Department of Energy

under Contract DE-AC06-76RLO 1830

Pacific Northwest National Laboratory

Richland, Washington 



\section{DISCLAIMER}

This report was prepared as an account of work sponsored by an agency of the United States Government. Neither the United States Government nor any agency thereof, nor any of their employees, make any warranty, express or implied, or assumes any legal liability or. responsibility for the accuracy, completeness, or usefulness of any information, apparatus, product, or process disclosed, or represents that its use would not infringe privately owned rights. Reference herein to any specific commercial product, process, or service by trade name, trademark, manufacturer, or otherwise does not necessarily constitute or imply its endorsement, recommendation, or favoring by the United States Government or any agency thereof. The views and opinions of authors expressed herein do not necessarily state or reflect those of the United States Government or any agency thereof. 


\section{DISCLAIMER}

Portions of this document may be illegible in electronic image products. Images are produced from the best available original document. 


\section{Abstract}

To remediate gas retention in the floating crust layer and the potential for buoyant displacement gas releases from below the crust, waste will be transferred out of Hanford Tank 241-SY-101 (SY-101) in the fall of 1999 and back-diluted with water in several steps of about 100,000 gallons each. To evaluate the effects of back-dilution on the crust, a static buoyancy model is derived that predicts crust and liquid surface elevations as a function of mixing efficiency and volume of water added during transfer and back-dilution. Experimental results are presented that demonstrate the basic physics involved and verify the operation of the models.

A dissolution model is also developed, to evaluate the effects of dissolution of solids on crust floatation. The model includes dissolution of solids suspended in the slurry as well as in the crust layers. The inventory and location of insoluble solids after dissolution of the soluble fraction are also tracked. The buoyancy model is applied to predict the crust behavior for the first back-dilution step in SY-101. Specific concerns addressed include conditions that could cause the crust to sink and back-dilution requirements that keep the base of the crust well above the mixer pump inlet. 



\section{Summary}

The crust layer in Hanford Tank 241-SY-101 (SY-101) is a dynamic system in which retained gas makes the crust more buoyant than the mixed slurry on which it floats. Gas retention in the crust has increased since the mixer pump was installed in 1993, causing accelerated waste level growth and accumulation of a large volume of flammable gas.

To remediate gas retention in the crust and the potential for buoyant displacement gas releases from below the crust, it is planned is to transfer some of the waste out of the tank and replace it (back-dilute) with water in several steps of about 100,000 gallons each. In the first back-dilution, water will be added at the lowest possible elevations in the tank at a low flow rate to maximize mixing and ensure that the transfer and back-dilution processes keep the base of the crust layer well above the mixer pump inlet.

A detailed crust buoyancy model is needed to predict crust base elevation resulting from various back-dilution scenarios. Because the crust is floating, it can be modeled with simple hydrostatic principles. This report documents the derivation of crust buoyancy models and the predictions of crust behavior as a function of diluent mixing efficiency. First, a base buoyancy model is derived to describe pre-dilution conditions. Based on these conditions, models were derived to predict the perturbations resulting from dilution for three cases: i) volume of diluent not sufficient to submerge or float the crust, 2) crust submerged in the diluent (mixture is less dense than the crust), and, 3) crust floats on the diluent (mixture is more dense than the crust).

Simple experiments were performed using both a weighted bottle and a porous matrix of Styrofoam ${ }^{\circledR}$ beads and copper pellets to model the crust. These tests verified the model and demonstrated the salient features of crust behavior. In each test, water was added with little or no mixing to a container of heavier fluid with an object floating in it. The results demonstrated that, even if the object is heavier than water, it feels the buoyant force of the water and rises some distance out of the heavier fluid. If the object is lighter than water, it rises completely out of the heavier fluid and floats entirely in the water.

Solids dissolution is calculated under the basic assumption that soluble solids will dissolve until the liquid mixture of dissolved solids and water is in equilibrium. The mass of dilution water required to dissolve a given mass of solids is therefore equal to the product of the solids mass to be dissolved, the fraction of the solids that are soluble, and ratio of the mass of water to the mass of dissolved solids in the saturated liquid.

As water is added below the crust, the density of the slurry above the injection point decreases by dilution from the added water. This is partially compensated for by the release of gas, which is assumed to be in proportion to the fraction of solids in the slurry that are dissolved. If there is no top dilution, the analysis assumes that the crust is unaffected until all the soluble solids are dissolved from the slurry. At that point, the excess water begins to dissolve the bubble slurry layer. Because the bubble slurry contains a disproportionately high volume of gas, dissolution of this layer will greatly increase the average crust density. If this happens, the diluted slurry will no longer be able to support the heavier crust, and the crust will sink. 
In the current plan, two locations will be used for low water addition: the transfer pump inlet, 96 inches from the tank bottom, and the mixer pump burrowing ring, 9 inches from the bottom. ${ }^{\text {(a) }}$ The lower the back-dilution water injection point, the larger the volume of slurry available to mix with the water. This means that the back-dilution volume would be less limited if water were added through the base of the mixer pump rather than through the transfer pump inlet.

Because the back-dilution volume is expected to be the same as the transfer volume in most cases, larger transfer volumes will result in an increasingly dilute slurry. At some point, the mixed slurry density will be too low to float the crust, and the back-dilution volume will need to be reduced to prevent the crust from sinking. With the back-dilution volume lower than the transfer volume the crust base will be lower, because the volume of the mixed liquid slurry decreases as transfer volume increases. Thus transfer volume is limited to the amount that allows maximum back-dilution to keep the crust base far enough above the mixer pump inlet to ensure effective operation. Because the mixer pump has operated effectively with the crust base as low as 295 inches, this level has been chosen as the lower limit.

The back-dilution limitations for the important scenarios with water injected at the 96 -inch transfer pump inlet and the 9-inch mixer pump burrowing ring are listed in the following table.

Table S-1. Volume Limits for Back-Dilution below Crust

\begin{tabular}{|c|c|c|}
\hline & $\begin{array}{l}\text { Water injected at } 96 \text { in. } \\
\text { transfer pump }\end{array}$ & $\begin{array}{l}\text { Water injected at 9-in. mixer } \\
\text { pump burrowing ring }\end{array}$ \\
\hline $\begin{array}{l}\text { Maximum transfer with equal } \\
\text { back-dilution allowable to } \\
\text { avoid sinking crust }\end{array}$ & $\begin{array}{c}90 \mathrm{kgal} \text { transfer with equal } \\
\text { back-dilution }\end{array}$ & $\begin{array}{c}120 \text { kgal transfer with equal } \\
\text { back-dilution }\end{array}$ \\
\hline $\begin{array}{l}\text { Maximum transfer and back- } \\
\text { dilution allowable to keep } \\
\text { crust above } 295 \text { in. without } \\
\text { sinking }\end{array}$ & $\begin{array}{l}143 \mathrm{kgal} \text { transfer } \\
\text { with } 80 \mathrm{kgal} \text { back-dilution }\end{array}$ & $\begin{array}{c}175 \mathrm{kgal} \text { transfer } \\
\text { with } 112 \mathrm{kgal} \text { back-dilution }\end{array}$ \\
\hline $\begin{array}{l}\text { Maximum transfer and back- } \\
\text { dilution allowable to keep } \\
\text { crust above } 295 \text { in. with at } \\
\text { least } 10 \mathrm{kgal} \text { margin to sinking }\end{array}$ & $\begin{array}{c}100 \mathrm{kgal} \text { transfer } \\
\text { with } 72.5 \mathrm{kgal} \text { back-dilution }\end{array}$ & $\begin{array}{c}125 \mathrm{kgal} \text { transfer } \\
\text { with } 103 \mathrm{kgal} \text { back-dilution }\end{array}$ \\
\hline $\begin{array}{l}\text { Maximum transfer with equal } \\
\text { back-dilution allowable to } \\
\text { avoid crust sinking with } 20 \\
\text { kgal of total added on top }\end{array}$ & $\begin{array}{l}128 \mathrm{kgal} \text { transfer with equal } \\
\text { back-dilution }\end{array}$ & $\begin{array}{c}160 \mathrm{kgal} \text { transfer with equal } \\
\text { back-dilution }\end{array}$ \\
\hline
\end{tabular}

(a) LMHC Interoffice Memo 79000-99-053, from RE Raymond to the SY-101 Project Group, August 18, 1999. Subject: 241-SY-101 Mixer Pump Inlet Level and SY-101 mixer pump drawing H2-89953. 
The table shows that top dilution is very beneficial in providing operational flexibility to the transfer and back-dilution process. The crust base remains well above the 295 -inch minimum and does not limit transfer volume. In addition, there are no serious consequences related to gas release if moderate volumes of water are added on top of the crust layer. Recent history shows that the crust can be confidently thinned to 60 inches without releasing bubble slurry. This requires approximately $50 \mathrm{kgal}$ of top dilution. Even if the entire bubble slurry layer were suddenly released to the headspace, the hydrogen concentration would be just above $50 \%$ of the LFL after a $100 \mathrm{kgal}$ transfer and under $50 \%$ of the LFL after a $150 \mathrm{kgal}$ transfer.

We conclude that, with proper planning, a 100-150 kgal transfer and equal back-dilution can be accomplished in the fall of 1999 without danger of sinking the crust or releasing gas from the bubble slurry. The greatest margin of safety is achieved if a significant fraction of the backdilution water is placed on top of the crust. 


\section{Contents}

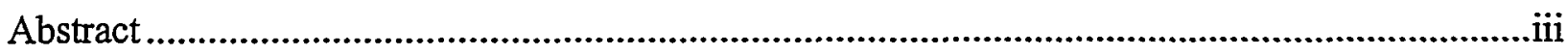

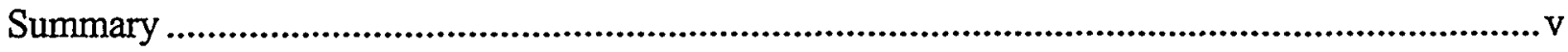

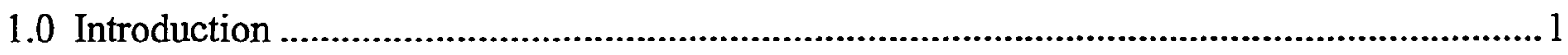

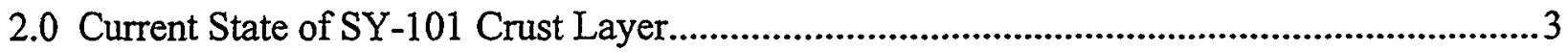

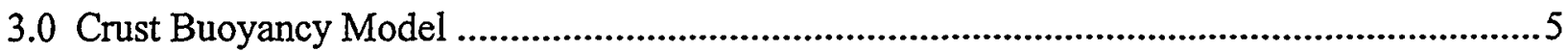

3.1 Reference Buoyancy Model for Crust Floatation ......................................................5

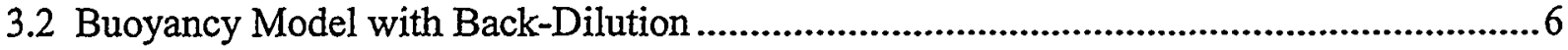

3.2.1 Partial Submergence or Floatation .....................................................................

3.2.2 Crust Completely Submerged in Diluent.......................................................... 8

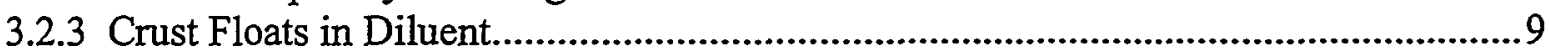

3.3 Experimental Demonstration of Crust Buoyancy Model ...........................................10

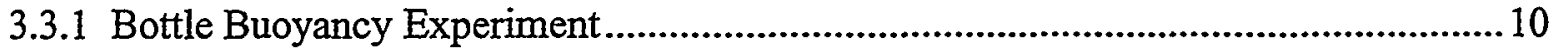

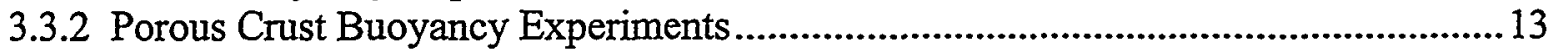

3.3.3 Comparison of Model Predictions with Experimental Results................................. 15

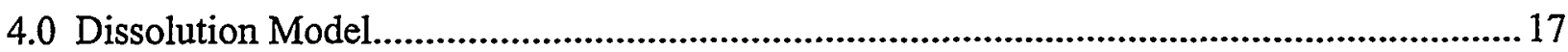

4.1 Dissolution Resulting from Low Water Addition......................................................... 18

4.2 Dissolution Resulting from Water Addition on Top of the Crust......................................222

4.3 Effect of Dissolution on Crust Buoyancy................................................................23

5.0 Crust Response to Transfer and Back-Dilution..........................................................29

5.1 Parameter Values for Current Crust Conditions .............................................................229

5.2 SY-101 Crust Buoyancy Predictions Including Dissolution ........................................... 31

5.2.1 Limits on Low Water Addition ..................................................................... 31

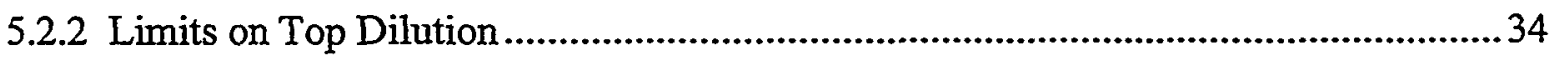

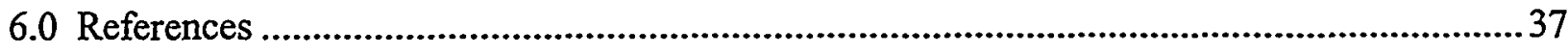

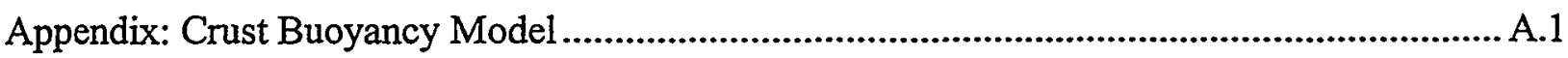




\section{Figures}

2.1 Crust Configuration as Indicated by Neutron Profiles..................................................... 3

2.2 Concept of Crust Configuration and Properties .............................................................

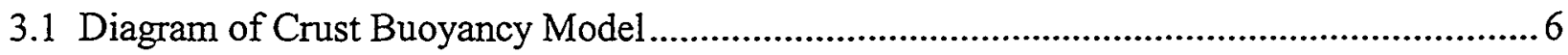

3.2 Small Volume of Water Added with Little or No Mixing ................................................. 7

3.3 Diluent Added so Crust Is Completely Submerged....................................................9

3.4 Diluent Mixture is Dense Enough to Support the Crust ................................................ 9

3.5 Bottle Buoyancy Tests for Case I Conditions .......................................................... 11

3.6 Bottle Buoyancy Tests for Case II Conditions ......................................................... 12

3.7 Simulated Crust with Density Greater Than that of Water ............................................. 13

3.8 Simulated Crust with Density Less Than that of Water.................................................. 14

4.1 Schematic of Back-Dilution Locations ................................................................... 17

5.1 Limitation on Low Water Addition to Prevent Crust Sinking ........................................ 33

5.2 Limitation on Low Water Addition after $40 \mathrm{kgal}$ Is Added to Crust Top.......................... 34

5.3 Effect of Adding Water to Crust Top after $150 \mathrm{kgal}$ Transfer .......................................35

\section{Tables}

3.1 Results of Bottle Buoyancy Tests for Case I Conditions ........................................... 11

3.2 Results of Bottle Buoyancy Tests for Case II Conditions.......................................... 12

3.3 Results of Porous Crust Buoyancy Tests for Case I Conditions ................................... 15

3.4 Results of Porous Crust Buoyancy Tests for Case II Conditions ................................... 15

3.5 Comparison of Buoyancy Model Predictions with Experimental Results.......................... 16

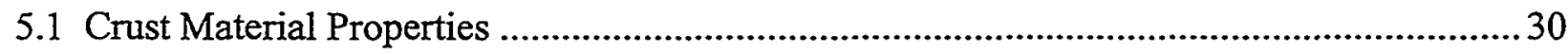

5.2 Base Parameter Values for Buoyancy Model...........................................................30

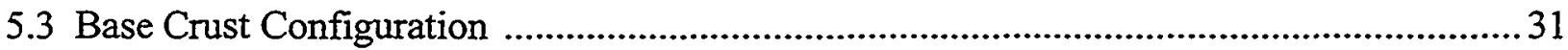




\subsection{Introduction}

The mixer pump installed in Hanford Tank 241-SY-101 (SY-101) in July 1993 has prevented the large buoyant displacement gas release events (BD GRE) the tank has exhibited historically. But the absence of periodic distuption from GREs and the action of mixing have caused the crust to grow by accumulating gas bubbles and solids from below. This has resulted in over 30 inches of waste level growth, and the flammable gas volume stored in the crust has become a hazard. To remediate gas retention in the crust and the potential for BD GREs from below the crust, SY-101 will be diluted in the fall of 1999 to dissolve a large fraction of the solids in the tank. Waste will be transferred out of the tank and replaced (back-diluted) with water in several steps of about 100,000 gallons each (Raymond 1999). Back-dilution water may be added at the transfer pump inlet, the base of the mixer pump, on top of the crust, or in some combination of these locations (Barton 1999).

The mixer pump will continue to be required to prevent formation of a deep nonconvective layer and resumption of BD GREs. Therefore, it is vital to ensure that the transfer and backdilution processes do not significantly degrade the pump's effectiveness. Part of the strategy to avoid mixing degradation is to keep the base of the crust layer well above the mixer pump inlet, which is 236 inches above the tank bottom. (a) The crust must also be prevented from sinking. The mixer pump may not be able to mobilize a sunken crust adequately to prevent BD GREs.

Because the crust is floating, it can be modeled with simple hydrostatic principles. Most basic is that the weight of the crust must be equal to the weight of fluid displaced. The amount of crust submerged depends on the density of the fluid it displaces. For the crust to float, the specific gravity of the fluid surrounding the crust must be greater than that of the crust. During back-dilution, the specific gravity of the fluid supporting the crust depends on how well the dilution water mixes with the slurry and how the crust dissolves.

This report documents the derivation and predictions of the crust buoyancy model and the predicted crust configuration as a function of mixing efficiency, back-dilution volume, and injection location. Section 2 describes the current state of the crust layer in SY-101. Section 3 presents the basic buoyancy model for crust floatation and provides a methodology for predicting the perturbations in crust buoyancy resulting from back-dilution both above and below the crust. This section also presents results of simple experiments that verify the model and demonstrate the basic behavior. Section 4 presents a model for determining the effect of dissolution of solids on the volume and density (and hence the mass) of the crust and the liquid slurry. Section 5 predicts the limits needed on transfer and back-dilution volumes to ensure that the crust does not sink and always floats with its base well above the level of the mixer pump inlet. References are listed in Section 6.

(a) Lockheed Martin Interoffice Memo 79000-99-053, RE Raymond to SY-101 Project Group, August 18, 1999. Subject: 241-SY-101 Mixer Pump Inlet Level. 



\subsection{Current State of SY-101 Crust Layer}

Measurements show that the top of the crust is currently about 432 inches above the tank bottom. Neutron and gamma probe data indicate that the crust base is about 310 inches from the bottom. The free liquid level in the tank is estimated at roughly 414 inches. These data indicate that the crust is about 120 inches thick and floats on the liquid with almost two feet of "freeboard" exposed above the liquid level. This configuration is the result of a redistribution event that occurred from mid-March through early May 1999, during which the base of the crust dropped about 30 inches. There was concurrently an abrupt and sustained increase in pumpinduced gas releases and a gradual reversal of the level rise trend. The crust has remained approximately in its current condition since June 1999. Before the redistribution event, void fraction instrument (VFI) (Stewart et al. 1998) and retained gas sampler (RGS) (Mahoney et al. 1999) void measurements along with the first neutron/gamma profiles showed that a high-void layer more than a foot thick may have existed at the base of the crust. Upward migration and dispersal of the gas in this layer may explain the redistribution. Analysis indicates that the average void fraction decreased as the crust thickness increased, so the total stored gas volume in the crust remained roughly constant. Neutron probe data after July 1999 show that a high void layer about 10 inches thick has reformed at the new crust base level.

Recent neutron/gamma count profiles, temperature profiles, operation of the mechanical mitigation arm (MMA) in late May 1999, and penetration of the crust with the 40-inch spray lance in August 1999 show that the crust now consists of four distinct layers. From their physical characteristics and position, these layers are termed "bubble slurry," "paste," "wet clay," and "inferred freeboard." The neutron profiles are shown in Figure 2.1, and a conceptual understanding of the crust configuration is illustrated in Figure 2.2.

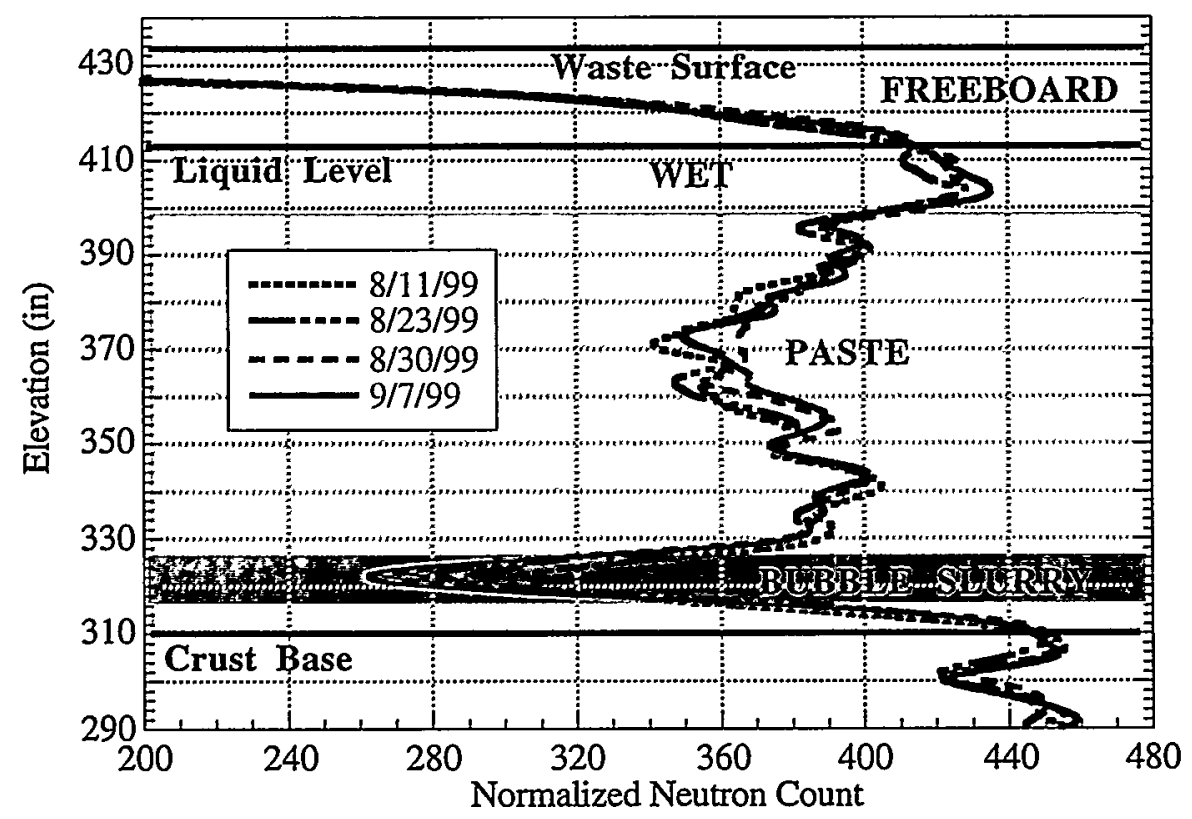

Figure 2.1. Crust Configuration as Indicated by Neutron Profiles 


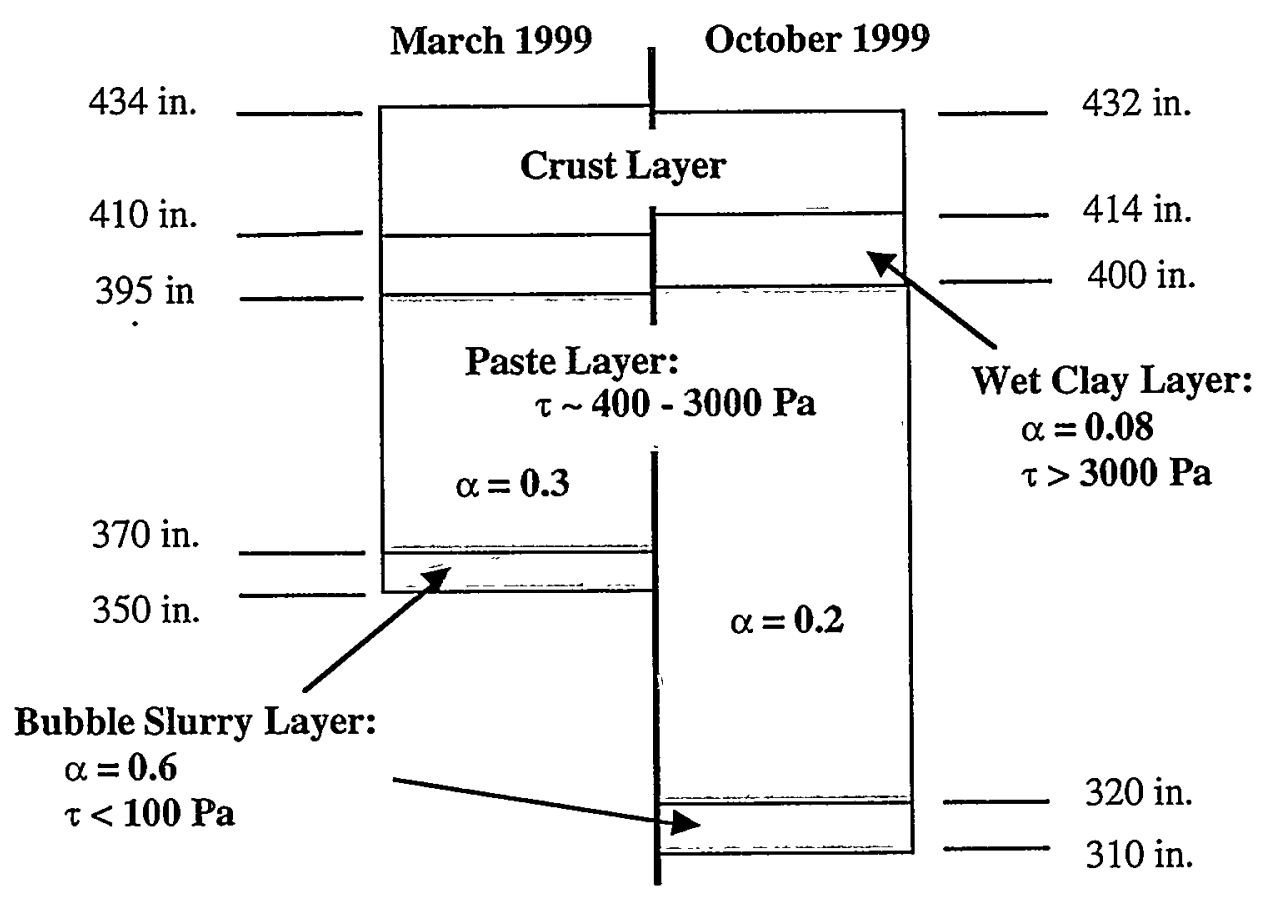

Figure 2.2. Concept of Crust Configuration and Properties

The "bubble slurry" is the bottom layer (310-320 inches) and consists of a relatively highvoid material. It has a void fraction that may be approaching 0.6 and a relatively low yield stress, estimated as less than $100 \mathrm{~Pa}$. The "paste" layer consists of the middle two-thirds (320-400 inches) and is relatively strong, approximately the consistency of stiff peanut butter or soft clay. It has a moderate void fraction, averaging about 0.2 , which decreases with height. Estimates of the torque required to rotate the MMA indicate a yield stress on the order of 400-3000 Pa. ${ }^{\text {(a) }}$ The "wet clay" layer (400-414 inches) lies just below the liquid level. It has a very low void fraction, estimated at 0.08 , and appears to be very strong. Although there are no direct measurements for this quantity, its yield stress is inferred to be greater than $3000 \mathrm{~Pa}$. This layer may also contain old "wastebergs" that existed prior to mixing, but it is not clear whether they could still be distinguished from the surrounding material.

The top sixth of the crust (414-432 inches) is the porous broken material above the liquid level and composes the current freeboard. Water added on the waste surface readily flows into this layer. Although individual fragments are quite strong and brittle, this layer has no strength as a unit. The height of vertical ledges visible after dissolution by flush water and estimated resistance to the cruciform lance penetration in August $1999^{(\mathrm{a})}$ indicate a local yield stress greater than $10,000 \mathrm{~Pa}$.

(a) Wells BE and G Terrones. October 1999. Estimates of the Yield Stress in Shear of the Floating Crust Layer in Tank 241-SY-101. Letter Report TWS99.60, Pacific Northwest National Laboratory, Richland, Washington. 


\subsection{Crust Buoyancy Model}

This section presents an overview of the crust buoyancy model, which is used to determine the results presented in Section 5. The crust floats on the liquid slurry by the same physical principles as a bar of soap in a bathtub. The depth to which the crust is submerged, and whether or not it floats at all, is determined by the balance between the weight of the crust and the weight of the fluid it displaces. The buoyancy model is needed because transfer and back-dilution will alter the density of the fluid currently supporting the crust. The density of the crust may also change due to dissolution of solids, or by the porous crust freeboard absorbing some amount of the fluid in which it is submerged. This means that dilution operations will change the submerged depth of the crust and could even cause it to sink.

This section contains a conceptual description of the crust buoyancy model. Section 3.1 describes the basic model, with the main assumptions. Section 3.2 describes the three main variations to consider when using this model to determine crust buoyancy with back-dilution. In Section 3.3, model results are compared with experimental data from tests simulating crust behavior for several postulated back-dilution scenarios. The derivation is presented in detail in Appendix A.

\subsection{Reference Buoyancy Model for Crust Floatation}

The crust buoyancy model applies the simple physical principle discovered by Archimedes more than 2300 years ago: the weight of an object floating in a liquid must be equal to the volume of liquid displaced by the object. The crust is an object made up of solids, retained gas, and liquid held within the porous structure of the crust. The solid material in the crust is by itself too dense to float on the slurry; the crust floats only by virtue of trapped gas within the crust. Gas is assumed to be retained in the crust as isolated particle-displacing bubbles that constitute some specific void fraction relative to the total volume of the crust. The pores between particles are assumed to be completely saturated with liquid in the submerged portion of the crust.

The overall density of the submerged portion of the crust depends on its void fraction, solids volume fraction, and the liquid and solid phase densities. Similarly, the density of the slurry on which the crust floats depends on the solids volume fraction (due to particles suspended in the liquid), the void fraction (due to small gas bubbles that may be attached to the suspended particles), and the phase densities. The density of the unsubmerged portion of the crust (i.e., the "freeboard") also depends on its void fraction, solids volume fraction, and the liquid and solid phase densities. These quantities are not the same as in the submerged portion of the crust. The exposed crust contains open pores and void spaces surrounded by solid crust material. These pores and void spaces are assumed open to the headspace and therefore contain the headspace atmosphere. The pore spaces, but not the voids, are assumed to be partially filled or saturated with liquid due to capillary action. This model is illustrated schematically in Figure 3.1. 


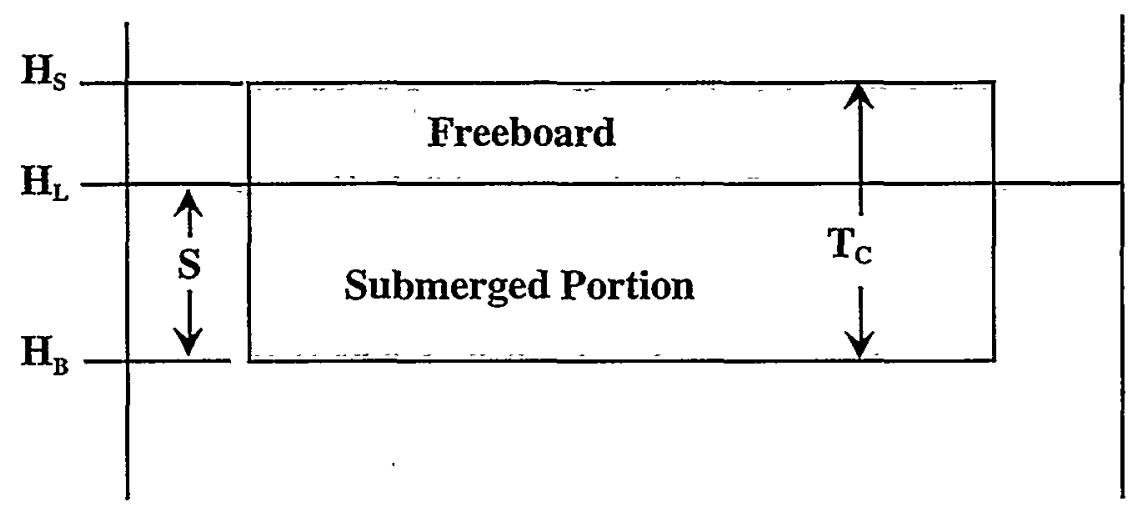

Figure 3.1. Diagram of Crust Buoyancy Model

Balancing the upward buoyancy forces and downward gravitational forces on the crust yields relationships to determine the depth the crust is submerged (S), the height of the liquid level (HL), the height of the crust surface (HS), and the height of the crust base (HB). The details of the derivation and formulation of these relationships are presented in Appendix A.

\subsection{Buoyancy Model with Back-Dilution}

The amount of mixing that occurs with injection of water during back-dilution under the crust determines the density of the liquid slurry the crust is floating on. The mixing of the liquid slurry and added water is expected to be very good at best and essentially nonexistent at worst. To express this range of possibilities for modeling purposes, back-dilution is assumed to form two distinct stratified layers in the liquid. The upper layer is assumed to be a homogeneous mixture of dilution water and some specific fraction of the original mixed slurry. The volume of mixed slurry divided by the volume of added water is defined as the mixing ratio. The lower layer is assumed to be essentially the same as the original undiluted slurry. This model also assumes that no solids dissolve when the crust comes in contact with the added water or unsaturated water-slurry solution (this assumption is relaxed in the model presented in Section 4.) The crust itself is assumed to have passages through which water can flow relatively easily, such that all hydrodynamic effects can be ignored. That is, the crust behaves purely as a hydrostatic system before, during, and after adding the dilution water.

Because the density of water is much lower than that of the slurry, any water that is added on top of the crust will initially penetrate only to the existing liquid level. Similarly, even when water is added below the crust, the diluent mixture of water and slurry will of necessity be lighter than the original slurry, and the diluent mixture will percolate up, through, and around the crust to stratify on top of the unmixed slurry. The crust will rise or sink until it displaces a sufficient volume of fluid to support its weight in the surrounding liquid. Depending on the amount of mixing, the diluent mixture density may result in the crust being either partially or wholly 
submerged in the liquid. The submerged portion of the crust may be supported entirely in the diluent mixture layer or partially in the diluent mixture layer and partially in the underlying original slurry layer.

In this section the crust buoyancy model is applied to various floatation scenarios. Section 3.2.1 describes the case in which there is only a small amount of dilution that is not enough to completely submerge the current crust freeboard; Section 3.2.2 discusses the case in which enough water is added for the resulting diluent mixture to fully submerge the crust, but there is insufficient mixing and the diluent mixture is not dense enough to support the crust. In this case, the lower part of the crust is supported by the original (undiluted) slurry, and the upper part of the crust is submerged in the diluent mixture. Section 3.2.3 discusses the effect of water added beneath the crust in sufficient volume and with enough mixing for the the crust to float on the diluent mixture, with no part of the crust submerged in the original slurry.

\subsubsection{Partial Submergence or Floatation}

When a small volume of dilution water is added on the top of the crust or a light diluent mixture percolates up to form a stratified layer on top of the slurry, the level at which the crust floats will change. If the added volume of water is small enough, the diluent mixture layer will not be deep enough to completely submerge or float the crust. The conditions before and after an addition of this type are as shown in Figure 3.2.

The density and void fraction of the originally submerged portion of the crust are assumed to remain unchanged. The density of the originally unsubmerged portion of the crust that remains unsubmerged, above the level of the diluent mixture, is also unchanged. In the newly submerged portion of the crust, however, the diluent mixture can penetrate the pores and voids that were formerly occupied by air. The buoyancy due to the additional subermergence increases the difference between the new crust surface level and the level of the undiluted slurry.

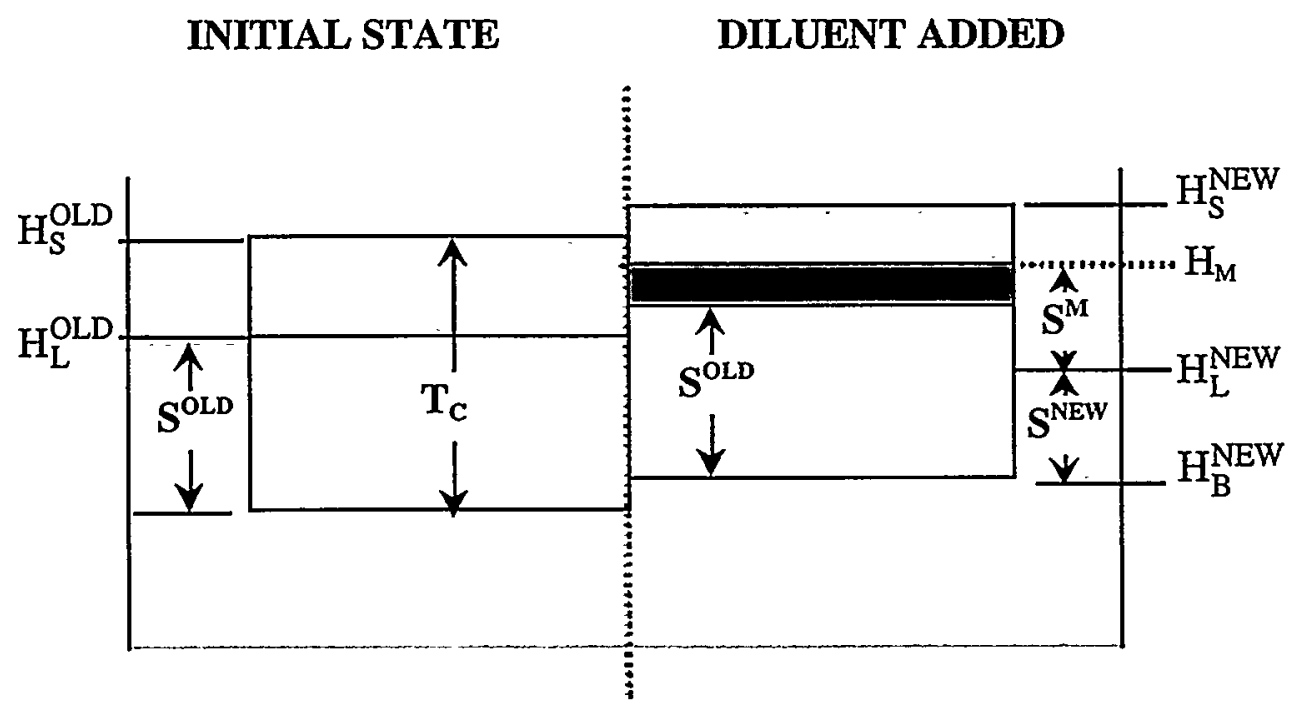

Figure 3.2. Small Volume of Water Added with Little or No Mixing 
Appendix A, Section A.1 contains a detailed derivation of this case for the crust buoyancy model, defining the relationships for the new liquid surface level, crust surface level, undiluted slurry liquid level, and the submerged depth of the crust. In addition, relationships for the density of the newly submerged crust freeboard and the density of the diluent mixture layer are derived. These are expessed in terms of the mixing ratio, $M$, for the diluent mixture. The mixing ratio is defined as the ratio of the volume of slurry that mixes with the water to form the diluent mixture to the volume of water added. It is assumed that volume is conserved while the two fluids mix. For pure water added so it does not mix at all with the slurry, $M=0$.

The new depth to which the crust is submerged can be calculated from the volume of water added. The model assumes that the diluent mixture fills the available air space in the pores and voids above the original liquid level in the crust freeboard plus any portion of the liquid surface area that is not occupied by crust (see Figure 3.2). This solution is applicable only if the crust is not completely submerged or is floating entirely in the diluent mixture. The volume of mixed diluent needed to just submerge the crust can be computed as a function of the crust thickness and the mixing ratio $M$. If the volume of water to be added is larger than this amount, the model is applied as described in Section 3.2.2. If the mixed diluent is of sufficient volume and density to completely float the crust, the model is applied as described in Section 3.2.3.

\subsubsection{Crust Completely Submerged in Diluent}

If the diluent is less dense than the bulk crust material, the diluent mixture will remain above the slurry level and the crust may be entirely submerged, as shown in Figure 3.3. The lower part of the crust is submerged in the original (undiluted) slurry, and the upper part is submerged in the new diluent mixture. The sum of the crust submergence depths is equal to the total crust thickness. The diluent mixture will also penetrate the porosity and void space throughout the newly submerged freeboard, which was originally above the liquid surface level before the water addition.

The new mixture level is determined from the amount of diluent in excess of that required to fully submerge the crust and can be expressed as a function of the mixing ratio, $M$, the volume of water added, and the volume of water required to just submerge the crust (determined from calculations using the model as applied in Section 3.2.1). The relationships that describe the conditions illustrated in Figure 3.3 are presented in detail in Appendix A, Section A.2.

This approach is valid only if the diluent density is less than that of the crust. When the density of the diluent mixture is just sufficient to float the crust, the submergence depth in the original (undiluted) slurry becomes zero. The mixing ratio and volume of water needed to achieve this state can be determined using the relationships described in Section A.2 of Appendix A. If the mixture ratio is greater than this value, the crust will float in the diluent mixture without any portion of it submerged in the original slurry. In that case, the crust buoyancy model is applied as described in Section 3.2.3. 


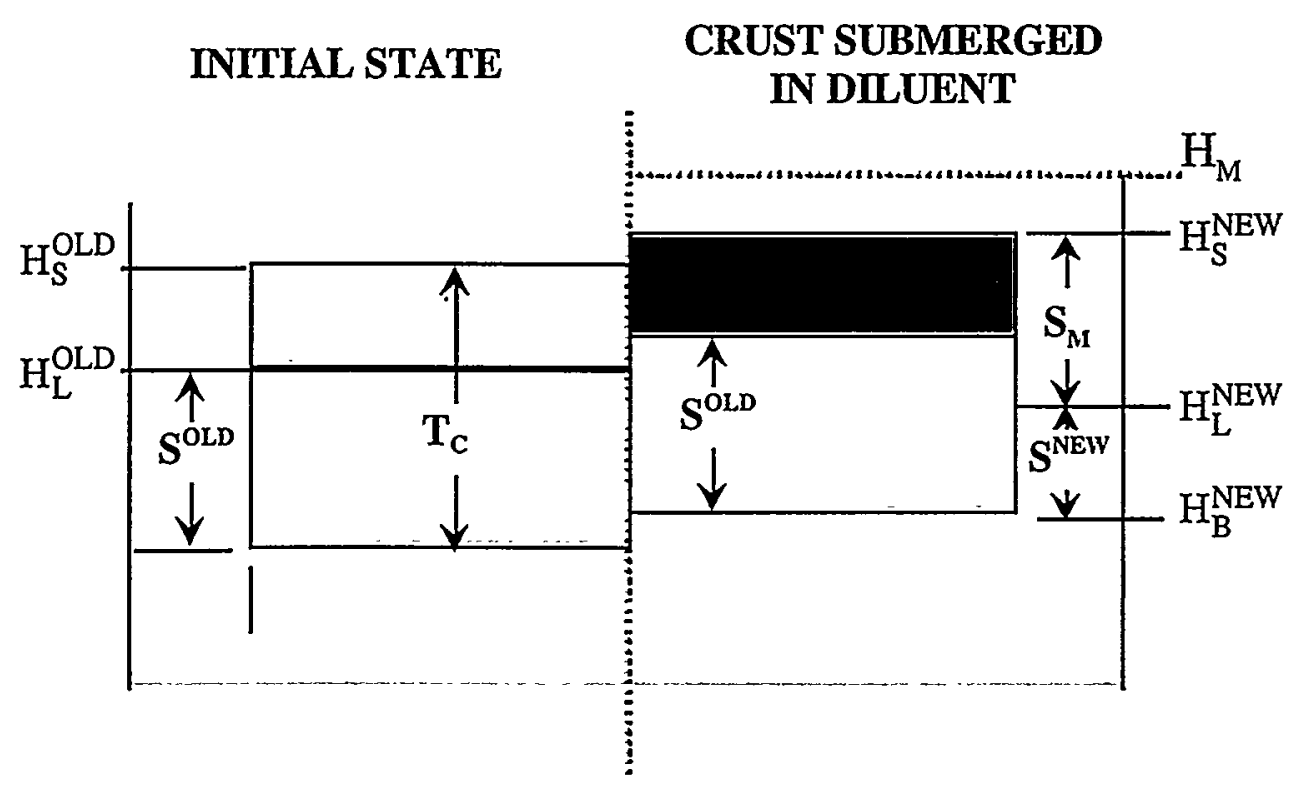

Figure 3.3. Diluent Added so Crust Is Completely Submerged

\subsubsection{Crust Floats in Diluent}

If enough mixing occurs for the diluent mixture to be denser than the bulk crust material, the crust will float entirely supported by the diluent mixture. This is illustrated schematically in Figure 3.4. This is similar to the original condition of crust buoyancy descibed in Section 3.1. The only difference is that the crust will be submerged to a greater depth, because the density of the diluent mixture must of necessity be somewhat less than that of the original slurry.

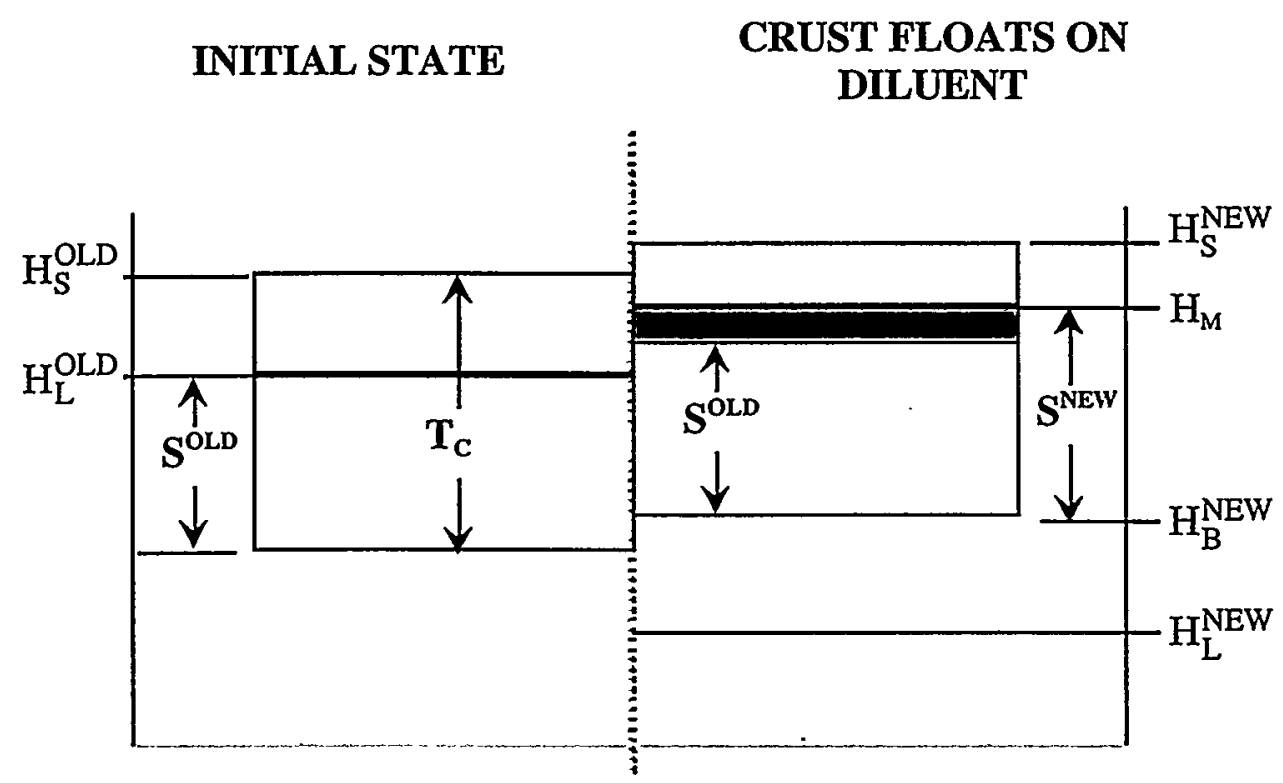

Figure 3.4. Diluent Mixture Is Dense Enough to Support the Crust 
The volume of diluent mixture needed to float the crust entirely in the diluent mixture layer is the volume of water required to form a mixed diluent that will submerge the crust such that its bottom is just at the interface between the diluent mixture layer and the original (undiluted) slurry layer. The volume of water needed to achieve this depth of submergence for the crust is a function of the thickness of the crust, its overall density, and the mixing ratio, $M$, which must be larger than the maximum value defined for the conditions described in Section 3.2.2. The detailed formulation of the model for this condition is presented in Appendix A, Section A.4.

\subsection{Experimental Demonstration of Crust Buoyancy Model}

Two simple experiments were run to verify the operation of the model and to demonstrate the basic behavior the model is designed to predict. In these experiments, a simple model of the buoyant crust was floated in a graduated cylinder containing a fluid that simulated the mixed slurry. One experiment used a sealed weighted bottle and another a porous cylinder to simulate the crust. Cases with the floating object denser than the diluent fluid were run for both experiments. Cases with the floating object less dense than the diluent fluid were also run for both experiments. Section 3.3.1 describes the sealed bottle tests. Section 3.3.2 describes the porous cylinder experiment. The experimental results are compared to model predictions in Section 3.3.3.

\subsubsection{Bottle Buoyancy Experiment}

In these experiments, the crust was simulated using a 571-mL Teflon ${ }^{\circledast}$ FEP bottle loaded with different weights of copper pellets. The bottle consists of two sections. The lower section is $124.5 \mathrm{~mm}$ and has an average cross-sectional area of $41.0 \mathrm{~cm}^{2}$; the upper section is $37.5 \mathrm{~mm}$ tall and has an average area cross-sectional area of $16.1 \mathrm{~cm}^{2}$. This configuration is shown in Figure 3.5. A $2000-\mathrm{mL}$ graduated cylinder with a cross-sectional area of $47.4 \mathrm{~cm}^{2}$ was used to model the tank.

Dichloromethane $\left(\mathrm{CH}_{2} \mathrm{Cl}_{2}\right)$, which has a density of $1.327 \mathrm{~g} / \mathrm{mL}$, was used to represent the mixed slurry. Water, which has a density of $1 \mathrm{~g} / \mathrm{mL}$, was added to represent the diluent. The two liquids are immiscible. Two cases were examined. In both cases, the densest material was the simulated slurry. In one of these cases, the bottle was denser than water, and in the other case, the bottle was less dense than water. The reference level for liquid level measurements was the bottom of the bottle before water was added.

The added water was measured by weight with an estimated uncertainty less than $0.1 \mathrm{~mL}$. Levels were read by marking the side of the graduated cylinder and measuring the distance between them with a rule. The maximum uncertainty in measuring the distance between two marks used for each referenced level datum is $\pm 2 \mathrm{~mm}$. The uncertainty in placing a mark was $<\sim 1 \mathrm{~mm}$ for the bottom of the crust model (model crust reference line) and $\pm 1 \mathrm{~mm}$ for the liquid surface level. The uncertainty was larger, $\sim 2 \mathrm{~mm}$, for the liquid/liquid interface because of the thickness of the miniscus. The overall standard deviation of the measurement is estimated by linear combination of uncertainties to be $\pm 3 \mathrm{~mm}$. 


\subsubsection{Case I: Bottle Is Submerged, $\rho_{\mathrm{SL}}>\rho_{\mathrm{C}}>\rho_{\mathrm{w}}$}

In Case I, the bottle weighed more than the volume of water it could displace but less than an equivalent volume of slurry. This was accomplished by adding copper pellets to the bottle until its total weight was $601.8 \mathrm{~g}$, which corresponds to a bulk density of $1.054 \mathrm{~g} / \mathrm{mL}$. Figure 3.5 shows schematically the changes in simulated crust and liquid levels with water additions, and the experimental results are summarized in Table 3.1. Because the fluids are immiscible, added water remains on top of the model slurry, appropriately simulating the diluent mixture layer on top of the (undiluted) slurry. The water surrounding the bottle exerts a buoyant force, lifting the bottle out of the slurry, until enough water is added to completely submerge the bottle. After that there is no change in the bottle position or slurry level-only the water surface level rises.

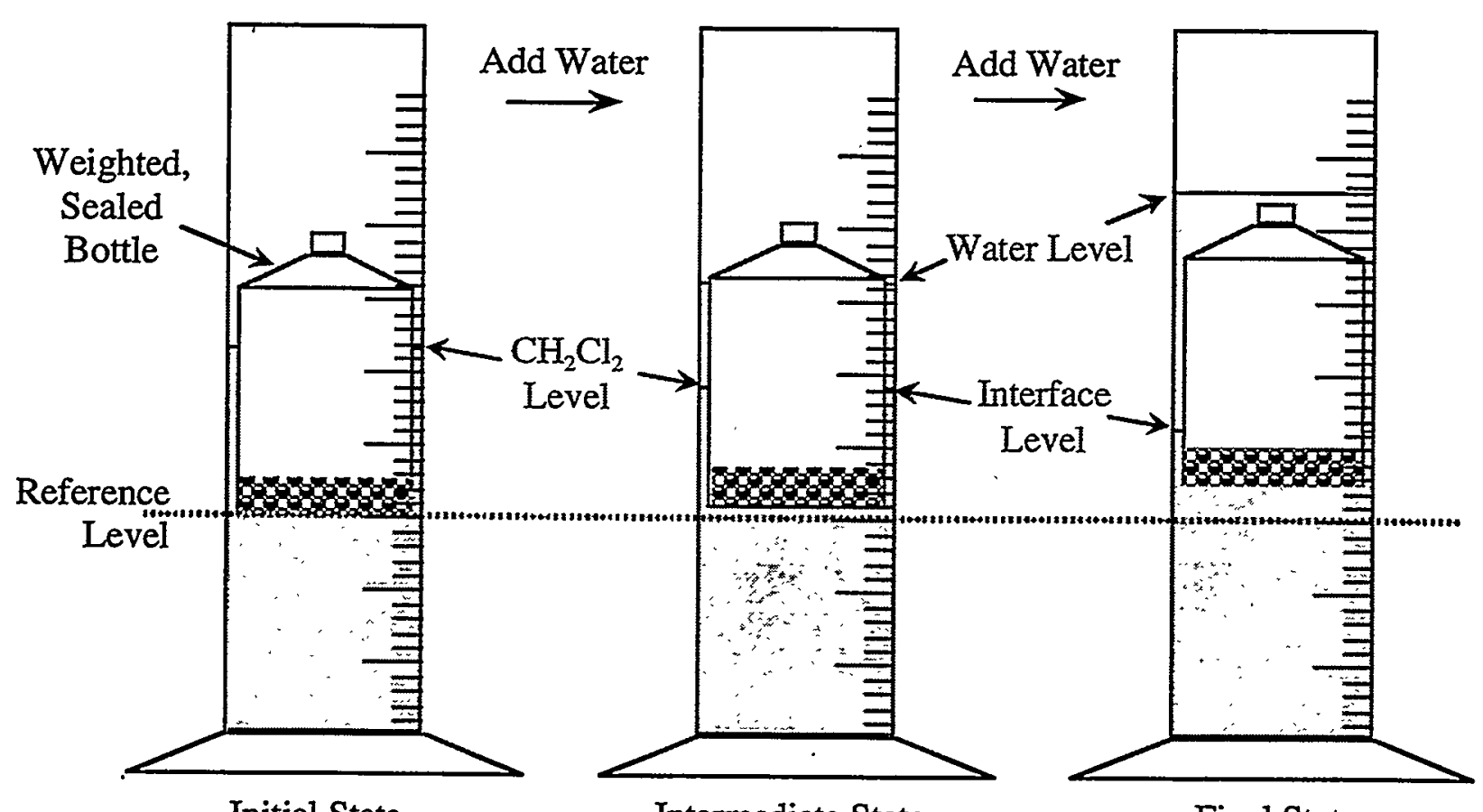

Figure 3.5. Bottle Buoyancy Tests for Case I Conditions ( $\left.\rho_{S L}>\rho_{C}>\rho_{W}\right)$

Table 3.1. Results of Bottle Buoyancy Tests for Case I Conditions $\left(\rho_{\mathrm{SL}}>\rho_{\mathrm{C}}>\rho_{\mathrm{W}}\right)$

\begin{tabular}{|l|c|c|c|}
\hline & $\begin{array}{c}\text { Bottom of bottle } \\
(\mathrm{mm})\end{array}$ & $\begin{array}{c}\mathrm{Ch}_{2} \mathrm{Cl}_{2} \text { Level } \\
(\mathrm{mm})\end{array}$ & $\begin{array}{c}\mathrm{H}_{2} \mathrm{O} \text { Level } \\
(\mathrm{mm})\end{array}$ \\
\hline $\mathrm{CH}_{2} \mathrm{Cl}_{2}$ only & 0 & 111.2 & $\mathrm{~N} / \mathrm{A}$ \\
\hline$+37.2 \mathrm{~g} \mathrm{H}_{2} \mathrm{O}$ (partially submerged & 5 & 75.2 & 131.7 \\
\hline$+152.3 \mathrm{~g} \mathrm{H}_{2} \mathrm{O}$ (completely submerged & 12.9 & 33.5 & 176.2 \\
\hline
\end{tabular}




\subsubsection{Case II: Bottle Floats on Diluent, $\rho_{\mathrm{SL}}>\rho_{\mathrm{w}}>\rho_{\mathrm{C}}$}

In Case II, the bottle weighed less than the volume of water it could displace. Consequently, it also weighed less than an equivalent volume of slurry because the slurry simulant $\left(\mathrm{CH}_{2} \mathrm{Cl}_{2}\right)$ is denser than water. The bottle weight was adjusted to $460.8 \mathrm{~g}$, which corresponds to a density of $0.807 \mathrm{~g} / \mathrm{mL}$. Figure 3.6 schematically depicts the changes in simulated crust and liquid levels with water additions. The results are summarized in Table 3.2.

As water is added, it exerts a buoyant force on the bottle. But because the bottle is lighter in this test, it rises farther out of the model slurry. At some point, the buoyant force of the water becomes sufficient to support the bottle. Further water addition raises the water level and the bottle, while the slurry level remains constant.

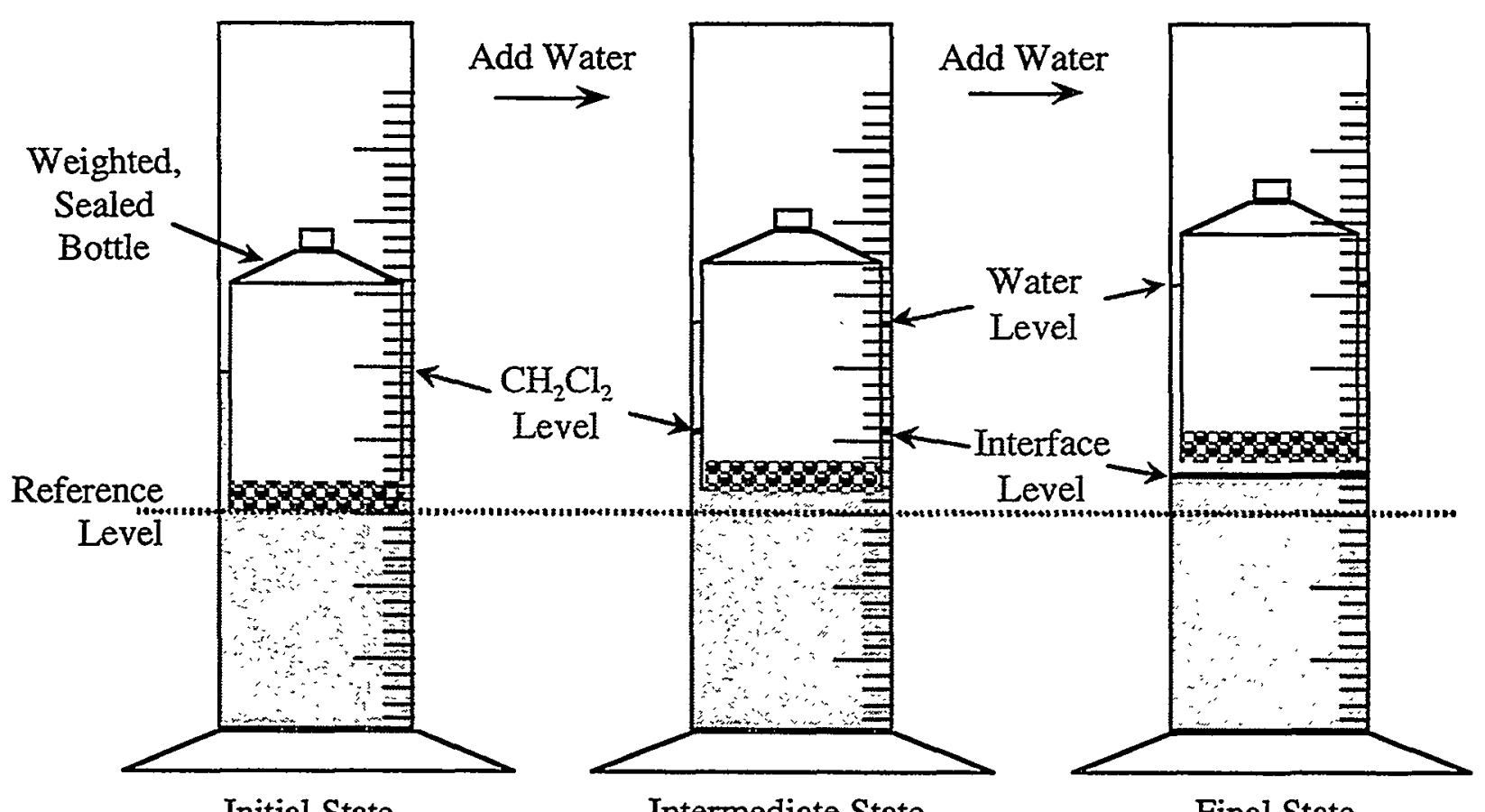

Initial State

Intermediate State

Final State

Figure 3.6. Bottle Buoyancy Tests for Case II Conditions $\left(\rho_{\mathrm{SL}}>\rho_{\mathrm{W}}>\rho_{\mathrm{C}}\right)$

Table 3.2. Results of Bottle Buoyancy Tests for Case II Conditions ( $\rho_{S L}>\rho_{W}>\rho_{C}$ )

\begin{tabular}{|l|c|c|c|}
\hline Condition & $\begin{array}{c}\text { Bottom of } \\
\text { bottle }(\mathrm{mm})\end{array}$ & $\begin{array}{c}\mathrm{CH}_{2} \mathrm{Cl}_{2} \\
\text { level }(\mathrm{mm})\end{array}$ & $\begin{array}{c}\mathrm{H}_{2} \mathrm{O} \text { level } \\
(\mathrm{mm})\end{array}$ \\
\hline $\mathrm{CH}_{2} \mathrm{Cl}_{2}$ only & 0 & 86.6 & N/A \\
\hline$+46.3 \mathrm{~g} \mathrm{H}_{2} \mathrm{O}$ (partially submerged in $\mathrm{CH}_{2} \mathrm{Cl}_{2}$ ) & 7.3 & 40.8 & 110.0 \\
\hline$+65.6 \mathrm{~g} \mathrm{H}_{2} \mathrm{O}$ (completely out of $\mathrm{CH}_{2} \mathrm{Cl}_{2}$ ) & 18.5 & 12.3 & 132.8 \\
\hline$+47.4 \mathrm{~g} \mathrm{H}_{2} \mathrm{O}$ (completely out of $\mathrm{CH}_{2} \mathrm{Cl}_{2}$ ) & 28.9 & 12.3 & 142.8 \\
\hline
\end{tabular}




\subsubsection{Porous Crust Buoyancy Experiments}

Porous crust models were constructed from a thin bottom layer of metal pellets $(\sim 0.4 \mathrm{~mm}$ diameter) and a thick top layer of Styrofoam ${ }^{\otimes}$ beads $(0.3-0.6 \mathrm{~cm}$ diameter). Individual pellets and beads were coated with epoxy resin, layered in a cylindrical mold while wet, and air-dried to form a solid porous crust. The cylindrical mold was $9.5-\mathrm{cm}$ in diameter and $5.1-\mathrm{cm}$ high, which corresponds to a volume of $360 \mathrm{~mL}$. Pictures of the simulated crust are shown in Figures 3.7 and 3.8. The one in Figure 3.7 is denser than water; the one in Figure 3.8 has a density less than that of water.

The crust porosity is defined as the difference between the volume of the mold and the volume of water displaced by the simulated crust made from the mold. Because of layering effects and differences in packing consistency, the porosity varies both vertically and radially. The vertical variation in porosity was checked by adding water in several stages with the porous crust held fixed in the vessel. The average porosity for each stage can be calculated from the change in height of water for each volume added: For the heavy crust, the porosity ranged from 0.34 to $>0.43$ (single-stage bulk measurement gave 0.43 ) and from 0.35 to 0.52 for the light crust (single-stage bulk measurement was 0.50 ). The standard deviation in porosity is estimated as \pm 0.07 . The bulk density of the crust was controlled by varying the relative amounts of metal pellets and Styrofoam beads.

The liquid used to model the slurry was a solution of $\sim 40 \%$ ferric chloride $\left(\mathrm{FeCl}_{3}\right)$ in water, which has a measured density of $1.38 \mathrm{~g} / \mathrm{mL}$. Water was the diluent. Experiments were

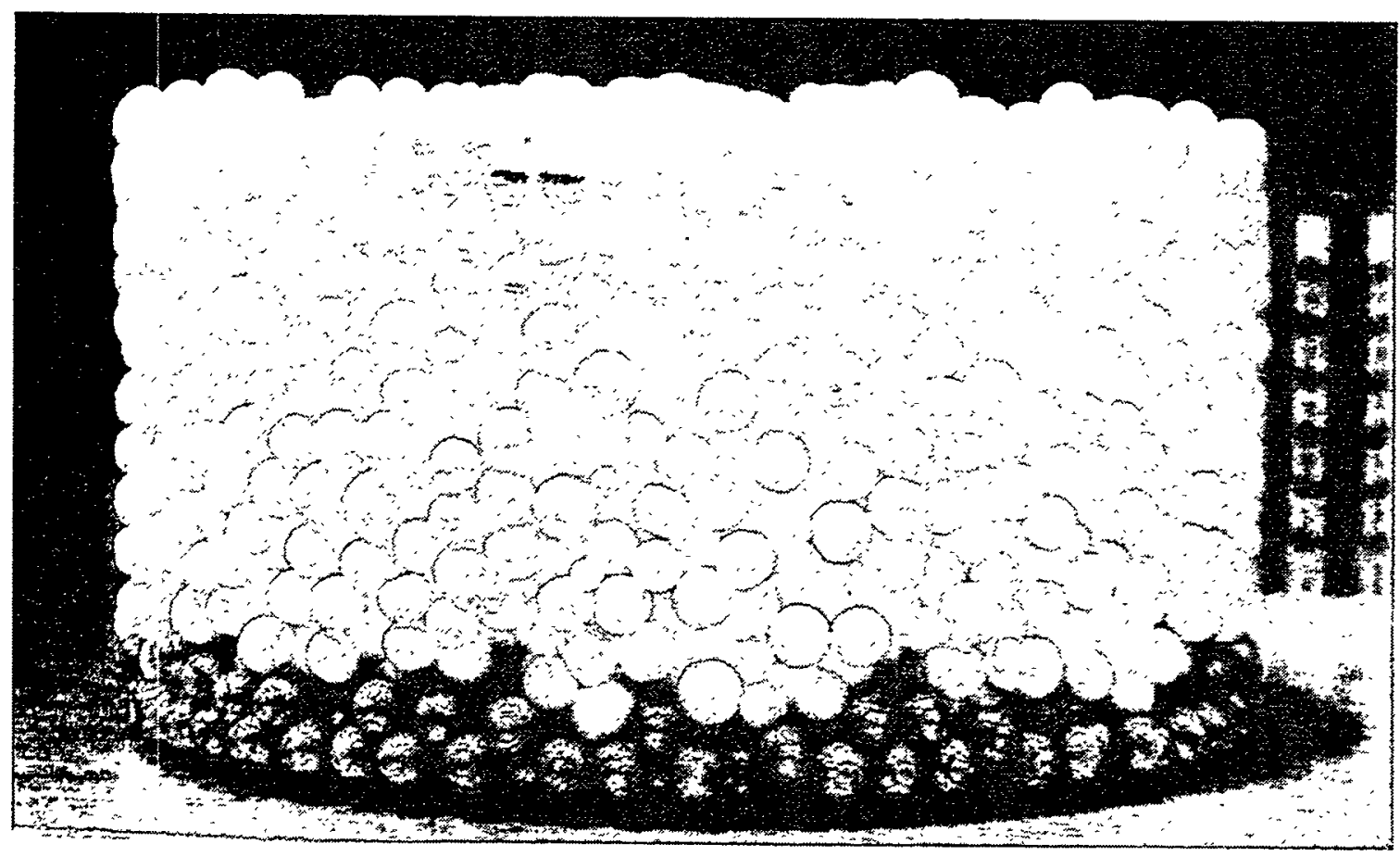

Figure 3.7. Simulated Crust with Density Greater Than that of Water $\left(\rho_{\mathrm{w}}<\rho_{C}\right)$ 


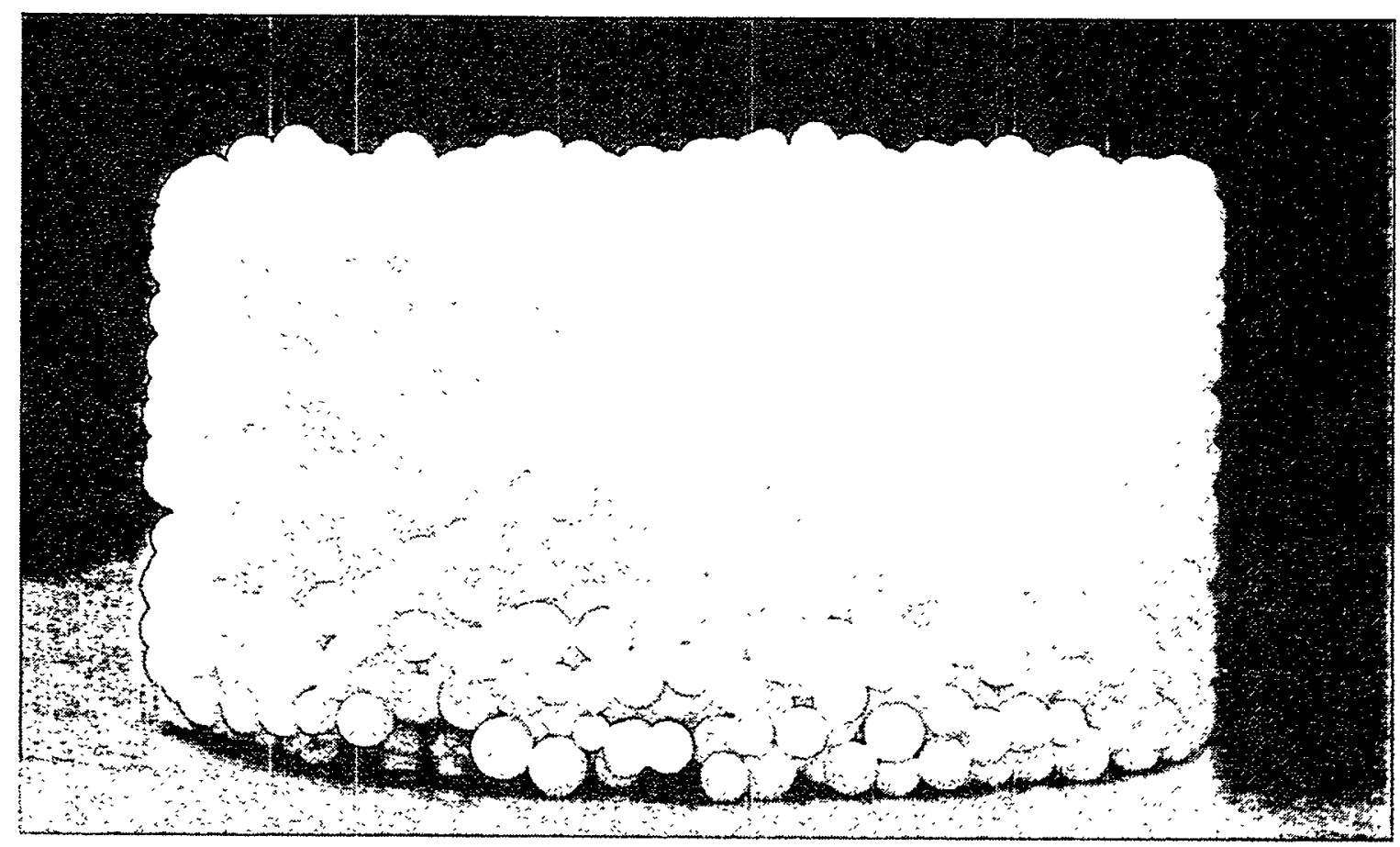

Figure 3.8. Simulated Crust with Density Less Than that of Water $\left(\rho_{C}<\rho_{W}\right)$

conducted in a 1-L beaker with a cross-sectional area of $\sim 79.6 \mathrm{~cm}^{2}$. As in the tests with the sealed bottle, the base of the crust prior to water addition was used as the reference point for fluid level measurements.

Because the water and the $\mathrm{FeCl}_{3}$ slurry are not immiscible in this test, some mixing is possible. However, water was added gently on top of the porous crust so that mixing was minimized. The effectiveness of this approach was verified by visual observation, since mixing is easy to detect due to the dark brown color of the $\mathrm{FeCl}_{3}$ solution. The interface was observed to remain quite sharp throughout the tests, so any effect of mixing was assumed very small and was neglected. The level measurement and added water volume uncertainties are estimated to be the same as for the bottle experiments, as described above in Section 3.3.1.

\subsubsection{Case I: Crust is Submerged, $\rho_{\mathrm{SL}}>\rho_{\mathrm{C}}>\rho_{\mathrm{W}}$}

The total crust weight was adjusted to $235 \mathrm{~g}$, which corresponded to a bulk density of $0.653 \mathrm{~g} / \mathrm{mL}$ (Figure 3.7). Water displacement measurement yielded a solid volume of $207 \mathrm{~mL}$, which is equivalent to a porosity of $42.5 \%$. Therefore, the true average density of solids in the crust is $1.14 \mathrm{~g} / \mathrm{mL}$, which is greater than that of water but less than that of the model slurry. Table 3.3 summarizes the changes in simulated crust and liquid levels with water additions.

The results are similar to the corresponding sealed bottle test described in Section 3.3.1.1. The diluent water exerts a buoyant force on the crust proportional to the volume of solids displaced so that the crust rises out of the $\mathrm{FeCl}_{3}$. This continues until water covers the crust. 
Table 3.3. Results of Porous Crust Buoyancy Tests for Case I Conditions ( $\left.\rho_{S L}>\rho_{C}>\rho_{W}\right)$

\begin{tabular}{|l|c|c|c|}
\hline Condition & $\begin{array}{c}\text { Bottom of crust } \\
(\mathrm{mm})\end{array}$ & $\begin{array}{c}\mathrm{FeCl}_{3} \text { Level } \\
(\mathrm{mm})\end{array}$ & $\begin{array}{c}\mathrm{H}_{2} \mathrm{O} \text { level } \\
(\mathrm{mm})\end{array}$ \\
\hline $\mathrm{FeCl}_{3}$ only & 0 & 43.7 & N/A \\
\hline$+49.8 \mathrm{~g} \mathrm{H}_{2} \mathrm{O}$ (partially submerged) & 5.2 & 36.5 & 50.9 \\
\hline$+50.2 \mathrm{~g} \mathrm{H}_{2} \mathrm{O}$ (partially submerged) & 10.1 & 32.2 & 59.8 \\
\hline$+149.2 \mathrm{~g} \mathrm{H}_{2} \mathrm{O}$ (completely submerged) & 14.4 & 30.0 & 77.5 \\
\hline
\end{tabular}

\subsubsection{Case II: Crust Floats on Diluent, $\rho_{\mathrm{SL}}>\rho_{\mathrm{W}}>\rho_{\mathrm{C}}$}

The total crust weight was adjusted to $119.8 \mathrm{~g}$, which corresponded to a bulk density of 0.333 $\mathrm{g} / \mathrm{mL}$ (see Figure 3.8.) Water displacement measurement yielded a solid volume of $180 \mathrm{~m}^{3}$ or, equivalently, a porosity of $50 \%$. Therefore, the true average density of solids in the crust is $0.666 \mathrm{~g} / \mathrm{mL}$, much lighter than water and also lighter than the simulated slurry. Table 3.4 summarizes the changes in simulated crust and liquid levels with water additions.

As with Case I, the results are similar to the corresponding sealed bottle test described in Section 3.3.1.2. The diluent water exerts a buoyant force on the crust proportional to the volume of solids displaced so that the crust rises out of the $\mathrm{FeCl}_{3}$. This continues until the crust floats in the water alone, with none of it submerged in the model slurry.

Table 3.4. Results of Porous Crust Buoyancy Tests for Case II Conditions ( $\left.\rho_{\mathrm{SL}}>\rho_{\mathrm{W}}>\rho_{\mathrm{C}}\right)$

\begin{tabular}{|l|r|r|r|}
\hline Condition & $\begin{array}{c}\text { Bottom of } \\
\text { crust }(\mathrm{mm})\end{array}$ & $\begin{array}{c}\mathrm{FeCl}_{3} \text { level } \\
(\mathrm{mm})\end{array}$ & $\begin{array}{c}\mathrm{H}_{2} \mathrm{O} \text { level } \\
(\mathrm{mm})\end{array}$ \\
\hline $\mathrm{FeCl}_{3}$ only & 0 & 28.9 & $\mathrm{~N} / \mathrm{A}$ \\
\hline$+50.1 \mathrm{~g} \mathrm{H}_{2} \mathrm{O}$ (partially submerged in $\mathrm{FeCl}_{3}$ ) & 4.6 & 24.8 & 35.2 \\
\hline$+50.2 \mathrm{~g} \mathrm{H}_{2} \mathrm{O}$ (partially submerged in $\mathrm{FeCl}_{3}$ ) & 9.2 & 21.7 & 43.2 \\
\hline$+133.9 \mathrm{~g} \mathrm{H}_{2} \mathrm{O}$ (completely out of $\left.\mathrm{FeCl}_{3}\right)$ & 22.5 & 18.8 & 63.9 \\
\hline
\end{tabular}

\subsubsection{Comparison of Model Predictions with Experimental Results}

The experiments above were compared with calculations using the crust buoyancy model described in Section 3. In each case, the basic buoyancy model was first applied to establish reference conditions consistent with the initial conditions that were the basis of the experimental measurements. The degassed level was adjusted so that the level of the crust base was zero for the reference condition. After the reference condition was determined, the partial floatation formulation from Section 3.2.1 was applied to all cases in which the heavy simulated crust was not completely submerged in water or the light simulated crust floated partially in water and partially in the slurry simulant. Submerged crust cases were modeled with the approach described in Section 3.2.2. The approach in Section 3.2.3 was used when the simulated crust floated in water entirely above the slurry simulant. Other modeling concerns are explained below. 
The bottle used to simulate the crust in the experiments described in Section 3.3.1 had a nonuniform cross-section where the top fourth of the bottle's height necked down to less than half the area of the bottom 75\% (see Figures 3.5 and 3.6). However, this area change was not considered explicitly in applying the crust buoyancy model to the test results. In the reference condition (with no water addition) and in the cases with partially submerged simulated crust cases, the part of the bottle that was submerged included only the part with uniform crosssection. When the bottle was fully submerged, it was necessary only to account for the total volume by assuming a uniform area equal to that of the straight section $\left(41 \mathrm{~cm}^{2}\right)$ and calculating an equivalent height for the bottle that gave the correct initial submergence. This adjusted height was $14 \mathrm{~cm}$ for the heavy bottle and $14.24 \mathrm{~cm}$ for the light one. Actual bottle height was $16.2 \mathrm{~cm}$.

The large pore diameter of the simulated porous crust allows liquid to flow through it with minimal resistance. Therefore, it was modeled as a uniform solid object with a cross-sectional area equal to the.product of the actual area $\left(70.9 \mathrm{~cm}^{2}\right)$ and measured average porosity $(42.5 \%$ for the simulated heavy crust and $50 \%$ for the light crust). The density was set equal to the measured average solids density, including both Styrofoam beads and copper pellets $(1.14 \mathrm{~g} / \mathrm{mL}$ for the heavy crust and $0.666 \mathrm{~g} / \mathrm{mL}$ for the light crust).

The experimental and analytical results are compared in Table 3.5. The differences between measured and predicted levels are typically less than $2 \mathrm{~mm}$, but the predicted slurry levels for the simulated heavy porous crust were 4.4 to $6.5 \mathrm{~mm}$ higher than measured values. This could be because of variable porosity in the simulated crust. The difference between measured and predicted values was still less than $3 \mathrm{~mm}$ in the light porous crust model.

Table 3.5. Comparison of Buoyancy Model Predictions with Experimental Results

\begin{tabular}{|c|c|c|c|c|c|c|c|c|}
\hline \multirow[b]{2}{*}{ Case } & \multirow{2}{*}{$\begin{array}{l}\text { Model } \\
\text { Used }\end{array}$} & \multirow{2}{*}{$\begin{array}{c}\text { Water Added } \\
(\mathrm{mL})\end{array}$} & \multicolumn{2}{|c|}{ Slurry level $(\mathrm{cm})$} & \multicolumn{2}{|c|}{ Crust base (cm) } & \multicolumn{2}{|c|}{ Water level $(\mathrm{cm})$} \\
\hline & & & Meas. & Pred. & Meas. & Pred. & Meas. & Pred. \\
\hline \multirow{3}{*}{$\begin{array}{l}\text { Heavy Bottle } \\
\text { (Sec. 4.1.1) }\end{array}$} & Base $^{(a)}$ & 0.0 & 11.12 & 11.12 & 0.0 & 0.0 & & \\
\hline & Partial $^{(\text {b) }}$ & 37.2 & 7.52 & 7.21 & 0.50 & 0.61 & 13.17 & 13.22 \\
\hline & Submg. ${ }^{(c)}$ & 189.5 & 3.35 & 3.56 & 1.29 & 1.18 & 17.62 & 17.74 \\
\hline \multirow{4}{*}{$\begin{array}{l}\text { Light Bottle } \\
\text { (Sec. 4.1.2) }\end{array}$} & Base & 0.0 & 8.66 & 8.66 & 0.0 & 0.0 & & \\
\hline & Partial & 46.3 & 4.08 & 3.80 & 0.73 & 0.76 & 11.00 & 11.28 \\
\hline & Float $^{(\mathrm{d})}$ & 111.9 & 1.23 & 1.17 & 1.85 & 2.06 & 13.28 & 13.57 \\
\hline & Float & 159.3 & 1.23 & 1.17 & 2.89 & 3.09 & 14.28 & 14.61 \\
\hline \multirow{4}{*}{$\begin{array}{l}\text { Heavy } \\
\text { Porous } \\
\text { (Sec. 4.2.1) }\end{array}$} & Base & 0.0 & 4.37 & 4.37 & 0.0 & 0.0 & & \\
\hline & Partial & 49.8 & 3.65 & 4.09 & 0.52 & 0.47 & 5.09 & 5.13 \\
\hline & Partial & 100.0 & 3.22 & 3.80 & 1.01 & 0.94 & 5.98 & 5.89 \\
\hline & Submg. & 249.2 & 3.00 & 3.65 & 1.44 & 1.19 & 7.75 & 7.89 \\
\hline \multirow{4}{*}{$\begin{array}{l}\text { Light Porous } \\
\text { (Sec. 4.2.2) }\end{array}$} & Base & 0.0 & 2.89 & 2.89 & 0.0 & 0.0 & & \\
\hline & Partial & 50.1 & 2.48 & 2.51 & 0.46 & 0.47 & 3.52 & 3.69 \\
\hline & Partial & 100.3 & 2.17 & 2.13 & 0.92 & 0.94 & 4.32 & 4.48 \\
\hline & Float & 234.2 & 1.88 & 1.60 & 2.25 & 2.43 & 6.39 & 6.43 \\
\hline \multicolumn{9}{|c|}{$\begin{array}{l}\text { (a) Base Model - Section } 2 \text {. } \\
\text { (b) Partially Submerged/Floating Model - Section 3.2.1. } \\
\text { (c) Submerged Crust Model - Section 3.2.2. } \\
\text { (d) Floating Crust Model - Section 3.2.3. } \\
\end{array}$} \\
\hline
\end{tabular}




\subsection{Dissolution Model}

After waste from the mixed slurry layer is transferred out of SY-101 into SY-102, water will be added both on top of and below the crust layer. The back-dilution scheme is sketched in Figure 4.1. Water will be placed on top of the crust through a flush line in the transfer pump pit. The water will fall 15-20 ft. to the waste surface. Because the water is much less dense than the liquid surrounding the crust, it will flow out across the surface, eventually filling the open space in the current freeboard. Since the water will flow through the freeboard in intimate contact with the solids, dissolution of the freeboard layer is expected to be relatively rapid (on the order of a day). Dissolution depth will probably be slightly greater in the vicinity of the water addition but is expected to be relatively uniform over the entire surface of the crust because of the barrier of the heavier salt-saturated liquid below.

Water will be added below the crust through the in-line dilution system at the inlet of the transfer pump, 96 inches above the tank bottom. Because water is much lighter than the slurry, it will rise as a plume, mixing with the slurry as it goes. Mixing above the injection point is predicted to be very effective with little stratification (Antoniak and Meyer 1999). The solids suspended in the slurry are quite small and are expected to dissolve rapidly in contact with the water. Assuming pure diffusion, a one-micron particle is $99 \%$ dissolved in less than one second. Diffusion alone will dissolve $99 \%$ of a 10 -micron particle or $90 \%$ of a 100 -micron particle in about one minute (Cussler 1984).

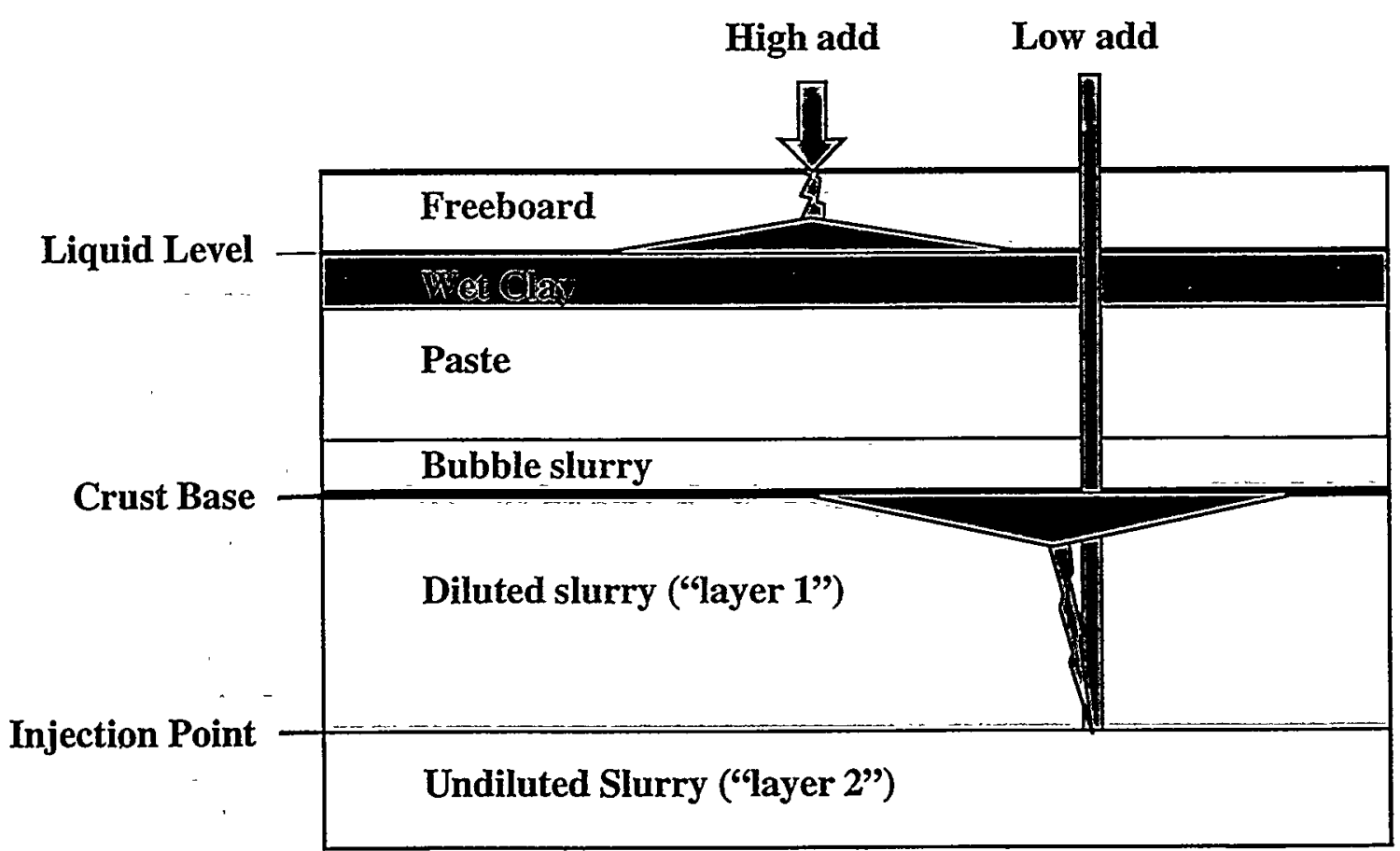

Figure 4.1. Schematic of Back-Dilution Locations 
Essentially no mixing or dissolution of suspended solids can be expected in the layer of slurry below the water injection point unless the mixer pump is run. Even then, mixing will be limited if a large density gradient has formed. However, there is also provision for adding water through the "burrowing ring" at the base of the mixer pump. The nozzles in the burrowing ring exit through holes in the bottom velocity plate, 9 inches from the tank bottom. ${ }^{(a)}$ Adding water at this elevation ensures that essentially all of the soluble suspended solids in the entire slurry layer will be dissolved if enough water is added. (In this analysis, dissolution of the additional solids that may be present in the loosely settled layer 50-60 inches from the tank bottom is ignored.)

Solids dissolution is calculated under the basic assumption that soluble solids will dissolve until the liquid mixture of dissolved solids and water is in equilibrium. The mass of dilution water required to dissolve a given mass of solids is therefore equal to the product of the solids mass to be dissolved, the fraction of the solids that are soluble, and ratio of the mass of water to the mass of dissolved solids in the saturated liquid.

Based on a statistical interpretation of SY-101 waste dilution data, the saturated liquid contains about 0.79 grams of water for every gram of dissolved solids at tank temperature. The solids mass is calculated based on a density of $2200 \mathrm{~kg} / \mathrm{m}^{3}$. This is used for undissolved and dissolved solids as well as the insoluble solids composing about $40 \%$ of the total solids mass. ${ }^{(b)}$ Water density is assumed to be $1000 \mathrm{~kg} / \mathrm{m}^{3}$. The resulting density of the saturated liquid at tank temperature is $1485 \mathrm{~kg} / \mathrm{m}^{3}$. If the mixed slurry layer has a solids volume fraction of 0.15 (see Section 5.1), the slurry reaches saturation at a mixing ratio of 6.8. The calculational model for dissolution due to water addition at low injection points and specific underlying assumptions are described in Section 4.1. The model for dissolution due to water addition on top of the crust is described in Section 4.2. Calculations of the buoyancy of the crust after dissolution by either low addition or top addition of water are presented in Section 4.3.

\subsection{Dissolution Resulting from Low Water Addition}

The mixed slurry layer contains solid particles and gas bubbles that are assumed to be uniformly distributed in suspension. Dissolution of suspended solids is expected to occur only in the fluid above the water injection point. The slurry layer above the level of the injection point is referred to as "Layer 1" in Figure 4.1, and the undiluted slurry below that level is "Layer 2." It is assumed that no dissolution or gas release will occur in Layer 2. Water is assumed to dissolve soluble solids in Layer 1 above the injection point until the liquid in that layer reaches saturation or until all available solids are dissolved. Insoluble particles are assumed to remain in suspension. If the diluent mixture is not yet saturated after all soluble solids in Layer 1 are dissolved, it is assumed that the crust begins to dissolve. It is further assumed that gas is released in proportion to the fraction of soluble solids dissolved. Insoluble solids left as the crust dissolves

(a) LMHC Interoffice Memo 79000-99-053 from RE Raymond to the SY-101 Project Group. August 18, 1999. Subject: 241-SY-101 Mixer Pump Inlet Level, and SY-101 Mixer Pump Drawing H2-89953.

(b) Kuhn WL and BE Wells. October 1999. Simplified Conceptual and Mathematical Model of Dilution of Tank 241-SY-101 Waste. Letter Report TWS00.06, Pacific Northwest National Laboratory, Richland, Washington. Results based on data given in NHC Internal Memo 82100-99-015 from Process Chemistry to NW Kirch, April 22, 1999: Dilution Studies of Tank 241-SY-101 Waste - Preliminary Results. 
from the bottom up are assumed to join the slurry. The model described below is used to determine how much of the soluble material is dissolved in Layer 1 and in the crust and how much gas is released in the process, for a given amount of water added.

The mass of undissolved soluble solids in the existing slurry layer above the injection point is computed as

$$
M_{S 1}=\left(1-\alpha_{S L}\right) \phi_{S L} \rho_{S} T_{1} A_{T}\left(1-F_{\text {insol }}\right)
$$

where

$\alpha_{\mathrm{SL}}=$ void fraction in the slurry

$\phi_{\mathrm{SL}}=$ volume fraction of undissolved solids in the slurry

$\rho_{\mathrm{s}}=$ density of undissolved solids $\left(2200 \mathrm{~kg} / \mathrm{m}^{3}\right)$

$\rho_{\mathrm{L}}=$ density of saturated mixture of dissolved solids and water $\left(1485 \mathrm{~kg} / \mathrm{m}^{3}\right)$

$\mathrm{T}_{1}=$ thickness of Layer 1 before dissolution, including the effect of transfer.

$$
T_{1}=T_{10}-V_{T} / A_{T}
$$

Where

$\mathrm{T}_{10}=$ thickness of Layer 1 before transfer

$\mathrm{V}_{\mathrm{T}}=$ volume of transfer

$\mathrm{A}_{\mathrm{T}}=$ tank cross-sectional area

$\mathrm{F}_{\text {insol }}=$ fraction of the total solids mass that is insoluble (40\%).

Similarly, the mass of saturated liquid in the slurry layer above the injection point is

$$
M_{L 1}=\left(1-\alpha_{S L}\right)\left(1-\phi_{S L}\right) \rho_{L} T_{1} A_{T}
$$

where $\rho_{\mathrm{L}}=$ density of saturated mixture of dissolved solids and water $\left(1485 \mathrm{~kg} / \mathrm{m}^{3}\right)$

The mass of water required to dissolve the soluble solids in the slurry is calculated from the mass of undissolved solids computed in Ea. 4.1 as

$$
\mathrm{M}_{\mathrm{W} 1}=\mathrm{EM}_{\mathrm{S} 1}
$$

where $\mathrm{E}=$ the ratio of water mass to dissolved solids mass in saturated liquid

For current tank conditions, $\mathrm{E}$ is defined as 0.79 grams of water per gram of dissolved solids. The mass of soluble solids that will be dissolved by a given volume of water is

$$
\Delta \mathrm{M}_{\mathrm{S} 1}=\min \left[\mathrm{M}_{\mathrm{Wl}}, \mathrm{M}_{\mathrm{WL}}\right] / \mathrm{E}
$$

where $\mathrm{M}_{\mathrm{WL}}=$ the total mass of water added below the crust. 
Any excess water available after dissolving all the soluble solids above the injection point $\left(M_{W_{L}}>M_{W_{1}}\right)$ is assumed to begin dissolving the solids in the base of the crust. Figure 4.1 shows a diagram of the crust layers, with the relatively high void bubble slurry layer at the bottom, the paste layer for the middle third or so of the crust, the wet clay layer above the paste layer, and capped by the relatively dry freeboard (see Section 2 for a more complete discussion of crust characteristics.) Crust layers are assumed to dissolve sequentially from the bottom up. How far the dissolution progresses depends on how much unsaturated diluent is available. When water is added low in the tank, dissolution is expected to affect only the bubble slurry and paste layers. Adding enough water to dissolve higher layers would almost certainly lower the slurry density sufficiently to sink the crust. It is necessary, therefore, to consider only the bubble slurry and paste layers when determining the mass of dissolved solids and gas release from the crust for low water additions.

The mass of soluble solids dissolved in the bubble slurry layer, $\Delta \mathrm{M}_{\mathrm{SB}}$, is calculated as

$$
\Delta \mathrm{M}_{\mathrm{SB}}=\min \left[\mathrm{M}_{\mathrm{WB}}, \mathrm{M}_{\mathrm{WL}}-\mathrm{M}_{\mathrm{Wl}}\right] / \mathrm{E}
$$

The mass of the soluble solids dissolved in the paste layer is given by

$$
\Delta \mathrm{M}_{\mathrm{SP}}=\min \left[\mathrm{M}_{\mathrm{WP}}-\Delta \mathrm{M}_{\mathrm{SPH}} \mathrm{E}, \mathrm{M}_{\mathrm{WL}}-\mathrm{M}_{\mathrm{W}_{1}}-\mathrm{M}_{\mathrm{WB}}\right] / \mathrm{E}
$$

where $\Delta \mathrm{M}_{\mathrm{SPH}}=$ mass of soluble solids in paste layer already dissolved by top dilution

The water masses $M_{W B}$ and $M_{W P}$ are the masses required to dissolve the solids in the two layers of the crust. The water mass is computed from the solids mass by applying Eq. (4.3). The mass of undissolved soluble solids, $\mathrm{M}_{\mathrm{SCi}}$, in the $\mathrm{i}^{\text {th }}$ crust layer is given by

$$
M_{S C i}=\rho_{S} T_{i} A_{T} \frac{A_{C}}{A_{T}}\left(1-\alpha_{i}\right) \phi_{C}\left(1-F_{\text {insol }}\right)
$$

The mass of saturated liquid, $\mathrm{M}_{\mathrm{LCi}}$, in the $\mathrm{i}^{\text {th }}$ crust layer is given by

$$
M_{L C i}=\rho_{L} T_{i} A_{T} \frac{A_{C}}{A_{T}}\left(1-\alpha_{i}\right)\left(1-\phi_{C}\right)
$$

where

$\alpha_{i} \quad=$ void fraction in crust layer $i$

$\phi_{C} \quad=$ volume fraction of undissolved solids in the crust

$\mathrm{T}_{\mathrm{i}} \quad$ = thickness of crust layer $\mathrm{i}$ before dissolution

$\mathrm{A}_{\mathrm{C}} / \mathrm{A}_{\mathrm{T}}=$ fraction of tank cross sectional area occupied by crust.

Besides the masses given by Eq. (4.7) and (4.8), solids and liquid also exist in the slurry surrounding the submerged crust below the freeboard. The contribution of mass of soluble solids in the surrounding slurry is expressed as

$$
M_{S S i}=\rho_{S} T_{i} A_{T}\left(1-\frac{A_{C}}{A_{T}}\right)\left(1-\alpha_{S L}\right) \phi_{S L}\left(1-F_{\text {insol }}\right)
$$


The mass of the liquid portion of the surrounding slurry is

$$
M_{L S i}=\rho_{L} T_{i} A_{T}\left(1-\frac{A_{C}}{A_{T}}\right)\left(1-\alpha_{S L}\right)\left(1-\phi_{S L}\right)
$$

The total mass of undissolved soluble solids in the submerged crust layers and surrounding slurry is the sum of the mass values given by Eq. (4.7) and (4.9); that is,

$$
\mathrm{M}_{\mathrm{Si}}=\mathrm{M}_{\mathrm{SCi}}+\mathrm{M}_{\mathrm{SSi}}
$$

The total mass of liquid in the submerged crust layers and surrounding slurry is the sum of the mass values given by Eq. (4.8) and (4.10); that is,

$$
\mathrm{M}_{\mathrm{Li}}=\mathrm{M}_{\mathrm{LCi}}+\mathrm{M}_{\mathrm{LSi}}
$$

The mass of insoluble solids in the $i^{\text {th }}$ crust layer and associated slurry can be calculated directly from the total soluble mass for the layer and insoluble mass fraction as

$$
\mathrm{M}_{\mathrm{ISi}}=\mathrm{M}_{\mathrm{Si}} \mathrm{F}_{\text {insol }} /\left(1-\mathrm{F}_{\text {insol }}\right)
$$

The assumption that mixed slurry surrounds the crust is conservative. The passages available to fluid flow around the crust are believed to be narrow, and the action of the mixer pump would not be expected to push particles up into them. The solids volume fraction around the crust is apparently not affected by the mixer pump because the waste level does not rise during pump runs. Gas bubbles, however, are expected to rise up through these passages on their way to the tank headspace. Including bubbles but not particles in the liquid around the crist would reduce the crust mass necessary to create the observed submergence depth and freeboard height. Assuming that particles are present has the effect of overpredicting by about $10 \%$ the water addition required to dissolve the crust.

The fraction of the $i^{\text {th }}$ crust layer remaining after dissolution and the mass of formerly interstitial liquid and insoluble solids freed by it are assumed proportional to the fraction of soluble solids mass that is dissolved. The void fraction, solids volume fractions and other properties of the remaining undissolved material are assumed to remain unchanged at their original values. The decrease in layer thickness, $\Delta \mathrm{T}_{\mathfrak{i}}$, is determined by

$$
\Delta \mathrm{T}_{\mathrm{i}}=\mathrm{T}_{\mathrm{i}} \frac{\Delta \mathrm{M}_{\mathrm{Si}}}{\mathrm{M}_{\mathrm{Si}}}
$$

The mass of interstitial liquid, $\Delta \mathrm{M}_{\mathrm{Li}}$ freed from the $\mathrm{i}^{\text {th }}$ crust layer by dissolution is given by

$$
\Delta \mathrm{M}_{\mathrm{Li}}=\mathrm{M}_{\mathrm{Li}} \frac{\Delta \mathrm{M}_{\mathrm{Si}}}{\mathrm{M}_{\mathrm{Si}}}
$$


Similarly, the mass of insoluble solids, $\Delta \mathrm{M}_{\mathrm{ISi}}$, freed from the $\mathrm{i}^{\text {th }}$ crust layer by dissolution is given by

$$
\Delta M_{I S i}=M_{I S i} \frac{\Delta M_{S i}}{M_{S i}}=\Delta M_{S i} \frac{F_{\text {insol }}}{1-F_{\text {insol }}}
$$

The freed insoluble solids, the liquid mixture from crust dissolution (consisting of the dissolved solids and freed interstitial liquid), and the added water are assumed to mix completely with the diluted waste in the slurry above the water injection point.

\subsection{Dissolution Resulting from Water Addition on Top of the Crust}

Dissolution of the upper crust layers is assumed to proceed sequentially from the top down. The water dissolves all the soluble solids available in the top layer first. Only then is any remaining unsaturated diluent mixture available to begin dissolving the next layer down. The top dilution model considers dissolution only of the freeboard, wet clay, and paste layers. Calculations for the wet clay and paste layers use the same model as that described in Section 4.1 above for dissolution of the bubble slurry and paste layers due to bottom dilution. The solids and interstitial liquid mass quantities are determined by Eq. (4.7) through (4.13). The amount of water required to dissolve the soluble solids can be calculated by applying Eq. (4.3) to the layer being considered.

Because it is above the liquid level, the freeboard layer is a special case. Its properties differ significantly from the submerged layers below, and it is not surrounded by mixed slurry. The soluble solids mass in the freeboard layer is computed by

$$
M_{S F}=\left(1-\alpha_{F}\right)\left(1-\omega_{F}\right) \rho_{S} T_{F}\left(\frac{A_{C}}{A_{T}}\right) A_{T}\left(1-F_{\text {insol }}\right)
$$

where

$\alpha_{\mathrm{F}}=$ void fraction (volume fraction of large voids) in the freeboard

$\omega_{\mathrm{F}}=$ porosity of the non-void region (which is subject to capillary action)

$\mathrm{T}_{\mathrm{F}}=$ thickness of the freeboard layer before dissolution.

The interstitial liquid mass in the freeboard layer is given by

$$
M_{L F}=\left(1-\alpha_{F}\right) \omega_{F} \psi \rho_{L} T_{F}\left(\frac{A_{C}}{A_{T}}\right) A_{T}
$$

where

$\psi=$ average liquid saturation in the non-void fraction due to capillary action (the porosity is filled with liquid when $\psi=1$ )

The fraction of the overall crust freeboard volume that is not solid or liquid can be computed as 


$$
\Omega_{\mathrm{F}}=\left(1-\alpha_{\mathrm{F}}\right) \omega_{\mathrm{F}}(1-\psi)+\alpha_{\mathrm{F}}
$$

The soluble solids mass in the freeboard that is dissolved by high water addition is calculated like Eq. (4.4) as

$$
\Delta \mathrm{M}_{\mathrm{SF}}=\min \left[\mathrm{M}_{\mathrm{WF}}, \mathrm{M}_{\mathrm{WH}}\right] / \mathrm{E}
$$

where

$\mathrm{M}_{\mathrm{WH}} \quad=$ the total volume of water added on top of the crust

$\mathrm{M}_{\mathrm{WF}} \quad=$ the mass of water to dissolve the soluble solids in the entire freeboard

$$
\left(\mathrm{M}_{\mathrm{WF}}=\mathrm{EM}_{\mathrm{SF}}\right) \text {. }
$$

Any excess water available after the entire freeboard layer is dissolved is assumed to first dissolve the wet clay layer and then the paste layer, in sequence. The mass of material that dissolves from the clay layer is expressed as follows:

$$
\Delta \mathrm{M}_{\mathrm{SC}}=\min \left[\mathrm{M}_{\mathrm{WC}}, \mathrm{M}_{\mathrm{WH}}-\mathrm{M}_{\mathrm{WF}}\right] / \mathrm{E}
$$

The mass of material that dissolves from the paste layer is given by

$$
\Delta M_{S P}=\min \left[M_{W P}, M_{W H}-M_{W F}-M_{W C}\right] / E
$$

Eq. (4.3) is applied to the paste layer and the wet clay layer to determine $M_{\mathrm{WP}}$ and $\mathrm{M}_{\mathrm{wc}}$, the mass of water needed to dissolve the soluble solids in each of these layers. The solids and liquid mass of the two non-freeboard layers are computed with Eq. (4.7) through (4.13).

The thickness of the remaining crust layers after dissolution and the mass of formerly intertitial liquid and insoluble solids freed by the dissolution are assumed proportional to the fraction of the total soluble solids mass dissolved. The void fraction, solids volume fractions, and other properties of the remaining undissolved material are assumed to remain unchanged at their original values. The decrease in layer thickness is determined by Eq. (4.14). The mass of interstitial liquid freed is calculated in Eq. (4.15). The mass of freed insoluble solids is determined using Eq. (4.16).

The liquid mixture consists of the dissolved solids and interstitial liquid freed from pores in the crust as a result of dissolution as well as the added water. This mixture is assumed to flow down through the crust and mix completely with the slurry supporting the crust. The insoluble solids freed by dissolution are conservatively assumed to remain as added weight on top of the crust.

\subsection{Effect of Dissolution on Crust Buoyancy}

Whether or not the crust will continue to float after dilution can be determined by applying the buoyancy model described in Section 3 to the diminished crust. If the new average crust density is still lower than that of the surrounding liquid, it will float. The density of the 
remaining crust is computed by summing up the remaining mass and dividing by the remaining volume. The remaining crust volume is given by the following expression:

$$
\begin{aligned}
\mathrm{V}_{\mathrm{CR}}= & \mathrm{A}_{\mathrm{T}} \frac{\mathrm{A}_{\mathrm{C}}}{\mathrm{A}_{\mathrm{T}}}\left[\left(1-\frac{\Delta \mathrm{T}_{\mathrm{F}}}{\mathrm{T}_{\mathrm{F}}}\right) \mathrm{T}_{\mathrm{F}}\left(1-\Omega_{\mathrm{F}}\right)+\left(1-\frac{\Delta \mathrm{T}_{\mathrm{C}}}{\mathrm{T}_{\mathrm{C}}}\right) \mathrm{T}_{\mathrm{C}}+\left(1-\frac{\Delta \mathrm{T}_{\mathrm{P}}}{\mathrm{T}_{\mathrm{P}}}\right) \mathrm{T}_{\mathrm{P}}+\left(1-\frac{\Delta \mathrm{T}_{\mathrm{B}}}{\mathrm{T}_{\mathrm{B}}}\right) \mathrm{T}_{\mathrm{B}}\right] \\
+ & \frac{\left(\Delta \mathrm{M}_{\mathrm{ISF}}+\Delta \mathrm{M}_{\mathrm{ISC}}+\Delta \mathrm{M}_{\mathrm{ISP}}\right)}{\rho_{\mathrm{SD}}}
\end{aligned}
$$

where

$\mathrm{T}_{\mathrm{i}} \quad=$ the original layer thickness

$\Delta \mathrm{T}_{\mathrm{i}} \quad=$ the change in thickness due to dissolution calculated by Eq. (4.9)

$\Omega_{\mathrm{F}} \quad=$ the fraction of the freeboard that is not solid or liquid, from Eq. (4.14)

$\rho_{\mathrm{SD}} \quad=$ the density of dissolved solids.

The last term on the right side of Eq. (4.23) represents the volume of the insoluble solids freed by dissolution resulting from water added on top of the crust. This material is assumed to remain on top of the crust; the masses are calculated using Eq. (4.16). The insoluble mass from the paste layer is only that part produced by top dilution.

The mass of the remaining crust that is contained in volume $V_{C R}$ is computed by multiplying the original layer mass (excluding the surrounding slurry) times the ratio of the remaining layer thickness to the original thickness and adding the mass of insoluble solids remaining on top of the crust. This is expressed by

$$
\begin{aligned}
\mathrm{M}_{\mathrm{CR}} & =\left(1-\frac{\Delta \mathrm{T}_{\mathrm{F}}}{\mathrm{T}_{\mathrm{F}}}\right)\left(\frac{\mathrm{M}_{\mathrm{SCF}}}{\left(1-\mathrm{F}_{\text {insol }}\right)}+\mathrm{M}_{\mathrm{LCF}}\right)+\left(1-\frac{\Delta \mathrm{T}_{\mathrm{C}}}{\mathrm{T}_{\mathrm{C}}}\right)\left(\frac{\mathrm{M}_{\mathrm{SCC}}}{\left(1-\mathrm{F}_{\text {insol }}\right)}+\mathrm{M}_{\mathrm{LCC}}\right) \\
& +\left(1-\frac{\Delta \mathrm{T}_{\mathrm{P}}}{\mathrm{T}_{\mathrm{P}}}\right)\left(\frac{\mathrm{M}_{\mathrm{SCP}}}{\left(1-\mathrm{F}_{\text {insol }}\right)}+\mathrm{M}_{\mathrm{LCP}}\right)+\left(1-\frac{\Delta \mathrm{T}_{\mathrm{B}}}{\mathrm{T}_{\mathrm{B}}}\right)\left(\frac{\mathrm{M}_{\mathrm{SCB}}}{\left(1-\mathrm{F}_{\text {insol }}\right)}+\mathrm{M}_{\mathrm{LCB}}\right) \\
& +\Delta \mathrm{M}_{\mathrm{ISF}}+\Delta \mathrm{M}_{\mathrm{ISC}}+\Delta \mathrm{M}_{\mathrm{ISP}}
\end{aligned}
$$

The original freeboard mass of soluble solids and interstitial liquid is given by Eq. (4.17) and (4.18), and the original masses of the submerged layers, excluding the surrounding slurry, is computed from Eq. (4.7) and (4.8). Dividing the soluble solids mass by $\left(1-\mathrm{F}_{\text {insol }}\right)$ gives the total solids mass. Note that only the insoluble solids mass freed from the paste layer due to top dilution is included in Eq. (4.24). That part freed by dissolution from the bottom up is assumed to mix with the slurry.

The average density of the remaining crust is simply the remaining mass divided by the remaining volume 


$$
\rho_{\mathrm{CR}}=\frac{\mathrm{M}_{\mathrm{CR}}}{\mathrm{V}_{\mathrm{CR}}}
$$

For the crust to float, the density of the slurry must exceed the density of the remaining crust, as computed by Eq. (4.25). The slurry density after transfer and back-dilution is determined by

- the mass of the original slurry liquid

- the mass of the suspended soluble solids in the slurry above the water injection point

- the mass of dilution water added above and below

- the total mass of dissolved solids, insoluble solids, and freed interstitial liquid resulting from crust dissolution

- the reduction in liquid volume due to gas release resulting from dissolution of slurry solids above the water injection point.

The liquid from dissolving the crust will not mix effectively with the underlying liquid if it is lighter than the slurry after dilution. In such a case, it will remain in a stratified layer on top of the slurry. It is therefore necessary to compute the slurry density in two steps. The first step is to calculate the density considering only the effects of dilution and gas release in the crust. If this density is high enough to permit mixing of the two liquid layers, the second step is to add in the effect of flowdown and mixing of the liquid portion of the dissolved crust.

Before the addition of liquid from flowdown of dissolved crust, the volume of the slurry above the injection point, ' $\mathrm{V}_{\mathrm{sl}}$, is the sum of three components. These are the amount of the original slurry volume that did not dissolve, the volume of the water added to the slurry that did not dissolve crust, and the volume of the dissolved solids and associated liquid. We conservatively assume at this point that the insoluble crust solids released by bottom dissolution have not yet joined the slurry. This sum can be expressed as

$$
\mathrm{V}_{1}=\mathrm{A}_{\mathrm{T}}\left(1-\frac{\Delta \mathrm{M}_{\mathrm{S} 1}}{\mathrm{M}_{\mathrm{S} 1}}\right) \mathrm{T}_{1}+\frac{\Delta \mathrm{M}_{\mathrm{S} 1}}{\rho_{\mathrm{SD}}}+\frac{\Delta \mathrm{M}_{\mathrm{IS} 1}}{\rho_{\mathrm{S}}}+\frac{\Delta \mathrm{M}_{\mathrm{L} 1}}{\rho_{\mathrm{L}}}+\frac{\mathrm{M}_{\mathrm{W} 1}}{\rho_{\mathrm{W}}}
$$

where

$\mathrm{T}_{1} \quad=$ the thickness of the slurry layer above the injection point after transfer but before back-dilution

$\Delta M_{\mathrm{L} 1}=\mathrm{M}_{\mathrm{L} 1} \Delta \mathrm{M}_{\mathrm{S} 1} / \mathrm{M}_{\mathrm{S1}}$ with $\mathrm{M}_{\mathrm{L} 1}$ from Eq. (4.2)

$\mathrm{M}_{\mathrm{W} 1}=\mathrm{EM}_{\mathrm{S} 1}$.

The quantities $\Delta \mathrm{M}_{\mathrm{Sl}}, \Delta \mathrm{M}_{\mathrm{IS} 1}$ and $\mathrm{M}_{\mathrm{SI}}$ in Eq. (4.26) are defined by Eq. (4.4), (4.16) and (4.1), respectively. The corresponding total mass, $\mathrm{M}_{1}$, is the sum of the original solids and liquid mass above the injection point and the water added

$$
M_{1}=M_{S 1}+M_{S 1}+M_{L 1}+M_{W 1}
$$

The density of the slurry before flowdown of the dissolved crust is the mass divided by the volume 


$$
\rho_{1}=\frac{M_{1}}{V_{1}}
$$

After flowdown, the volume and mass of the dissolved solids and freed liquid from both the crust and surrounding slurry are added to $V_{1}$ and $M_{1}$, respectively. The insoluble solids freed by dissolution of the bottom crust layers and the total water added above the crust must also be added to $V_{1}$ and $M_{1}$. This yields

$$
\begin{aligned}
\mathrm{V}_{1 \mathrm{~F}}= & \mathrm{V}_{1}+\frac{\Delta \mathrm{M}_{\mathrm{SF}}+\Delta \mathrm{M}_{\mathrm{SC}}+\Delta \mathrm{M}_{\mathrm{SP}}+\Delta \mathrm{M}_{\mathrm{SB}}}{\rho_{\mathrm{SD}}}+\frac{\Delta \mathrm{M}_{\mathrm{ISP}}+\Delta \mathrm{M}_{\mathrm{ISB}}}{\rho_{\mathrm{S}}} \\
& +\frac{\Delta \mathrm{M}_{\mathrm{LF}}+\Delta \mathrm{M}_{\mathrm{LC}}+\Delta \mathrm{M}_{\mathrm{LP}}+\Delta \mathrm{M}_{\mathrm{LB}}}{\rho_{\mathrm{L}}}+\frac{\mathrm{M}_{\mathrm{WH}}+\mathrm{M}_{\mathrm{WL}}-\mathrm{M}_{\mathrm{W} 1}}{\rho_{\mathrm{W}}}
\end{aligned}
$$

The new mass after flowdown is given by

$$
\begin{aligned}
\mathrm{M}_{1 \mathrm{~F}}= & \mathrm{M}_{1}+\Delta \mathrm{M}_{\mathrm{SF}}+\Delta \mathrm{M}_{\mathrm{SC}}+\Delta \mathrm{M}_{\mathrm{SP}}+\Delta \mathrm{M}_{\mathrm{SB}}+\Delta \mathrm{M}_{\mathrm{ISP}}+\Delta \mathrm{M}_{\mathrm{ISB}} \\
& +\Delta \mathrm{M}_{\mathrm{LF}}+\Delta \mathrm{M}_{\mathrm{LC}}+\Delta \mathrm{M}_{\mathrm{LP}}+\Delta \mathrm{M}_{\mathrm{LB}}+\mathrm{M}_{\mathrm{WH}}+\mathrm{M}_{\mathrm{WL}}-\mathrm{M}_{\mathrm{Wl}}
\end{aligned}
$$

The new density after flowdown is simply the result of Eq. (4.30) divided by Eq. (4.29):

$$
\rho_{1 F}=\frac{M_{1 F}}{V_{1 F}}
$$

The densities calculated using Eq. (4.28) and (4.31) assume perfect mixing in the slurry layer between the base of the crust and the water injection point. Of course, mixing will not be perfect, and some degree of stratification will occur. To characterize the degree of mixing that can be expected, the low back-dilution process was simulated using the TEMPEST code (Antoniak and Meyer 1999). The simulations predicted very good mixing, with only a slight density gradient between the injection point and the crust base. Stratification is conservatively included in calculations by assuming that the liquid forms two stratified layers rather than a smooth gradient. The densities of the two layers are computed by multiplying the density of each layer by a stratification factor. This factor is calculated as the ratio of the minimum slurry density to the maximum slurry density predicted in the simulations. The minimum specific gravity computed in TEMPEST for the liquid below the crust after adding $100 \mathrm{kgal}$ of water at the transfer pump inlet was 1.52, and the maximum was 1.56. This results in a stratification factor of $1.52 / 1.56=0.97$.

With the assumed stratification, the crust remaining after dilution/dissolution is predicted to float if the following condition is met:

$$
\rho_{\mathrm{CR}}<0.97 \cdot \min \left(\rho_{1}, \rho_{1 \mathrm{~F}}\right)
$$


If the crust remains floating after dilution and flowdown of the dissolved solids, we must determine if the crust base remains above the mixer pump inlet. Conservatively assuming that the crust is floating with zero freeboard, the level of the crust base is given by

$$
\mathrm{H}_{\mathrm{B}}=\mathrm{T}_{2}+\mathrm{V}_{1 \mathrm{~F}} / \mathrm{A}_{\mathrm{T}}
$$

where $T_{2}=$ the thickness of the undiluted slurry layer below the injection point.

The total crust thickness, $\mathrm{T}_{\mathrm{CR}}$, remaining after dissolution and flowdown is

$$
\mathrm{T}_{\mathrm{CR}}=\mathrm{T}_{0}-\Delta \mathrm{T}_{\mathrm{F}}-\Delta \mathrm{T}_{\mathrm{C}}-\Delta \mathrm{T}_{\mathrm{P}}-\Delta \mathrm{T}_{\mathrm{B}}
$$

where $T_{0}=$ the original crust thickness. (The insoluble solids left on top of the crust are not included in the thickness calculation.) 

......... 


\subsection{Crust Response to Transfer and Back-Dilution}

The buoyancy and dissolution models described in Sections 3 and 4 have been applied to determine transfer and back-dilution volumes that will not cause the crust to sink. It is also necessary to ensure that there will be sufficient water added to float the crust well above the mixer pump inlet. Input parameter values to characterize the crust and slurry for the buoyancy and dissolution models are established in Section 5.1. Section 5.2 presents the results obtained when the buoyancy model is applied in conjunction with the dissolution model. This section includes a parametric investigation to determine as a function of transfer volume the maximum volume of low water addition that will not sink the crust.

\subsection{Parameter Values for Current Crust Conditions}

The current condition and properties of the crust are needed to apply the buoyancy and dissolution models. The material properties of the crust mixed slurry have been reasonably well established by ball rheometer measurements (Stewart et al. 1995) and core samples (Reynolds 1993). Data from recent dissolution experiments on 1998 core samples were also interpreted to provide consistent values at tank temperature. ${ }^{(a)}$ These data are summarized in Table 5.1.

Reasonable estimates for the remaining parameters were developed by comparing the buoyancy model results with a series of measured levels. Table 5.2 lists data for specific dates for which input values are known with some confidence. The unknown parameters were adjusted to give the best match with the measured waste levels. The last column summarizes the best-estimate values for the parameters to be used in modeling current conditions. Measured values are shown in bold. The crust thickness was determined from temperature profiles from validation probe runs in the multi-function instrument trees (MITs). The crust and slurry void fractions were obtained from the VFI (Stewart et al. 1998) or RGS (Mahoney et al. 1999). ${ }^{\left({ }^{b}\right)}$ The measured waste surface level was assumed to be the value indicated by the Enraf ${ }^{\otimes}$ buoyancy gauge in riser 002 (1A). The liquid level was taken to be the value read on the Enraf in riser 001 (1C) after a water flush.

When the best-estimate values from Table 5.2 are applied with the current crust thickness, levels and estimated void fractions, the basic crust buoyancy model derived in Section 3 provides a description of the current crust configuration. The results are summarized in Table 5.3. The measured waste levels for mid-June 1999 match the predictions well. The crust is just over $3 \mathrm{~m}$ thick and about $86 \%$ submerged. It has an average void fraction of about 0.23 ,

(a) Kuhn WL and BE Wells. October 1999. Simplified Conceptual and Mathematical Model of Dilution of Tank 241-SY-101 Waste. Letter Report TWS00.06, Pacific Northwest National Laboratory, Richland, Washington. Results based on data in NHC Internal Memo 82100-99-015, from Process Chemistry to NW Kirch, April 22, 1999: Dilution Studies of Tank 241-SY-101 Waste-Preliminary Results.

(b) Slurry void fractions are currently estimated from trends in the mixer pump nozzle pressure during pump runs calibrated to RGS data. The pressure is approximately proportional to fluid density, which, in turn, is proportional to the non-void fraction. 
Table 5.1. Crust Material Properties

\begin{tabular}{|l|l|}
\hline Solids specific gravity - undissolved & 2.2 \\
\hline Solids specific gravity - dissolved & 2.2 \\
\hline Liquid specific gravity & 1.49 \\
\hline Fraction of solids mass that is insoluble & 0.4 \\
\hline $\begin{array}{l}\text { Crust submerged solids volume fraction } \\
\text { (results in a crust degassed specific gravity of 1.75) }\end{array}$ & 0.36 \\
\hline $\begin{array}{l}\text { Mixed slurry solids volume fraction } \\
\text { (results in a slurry degassed specific gravity of 1.60) }\end{array}$ & 0.15 \\
\hline
\end{tabular}

which has been divided into the four layers described in Section 2 . The bulk slurry void fraction is estimated as 0.027 from the mixer pump volute pressure trend. Two inches have been added to the degassed level to account for the approximately 2000 gallons of water added during operation of the mechanical mitigation $\operatorname{arm}^{(a)}$ in May and the water used in lancing and installation of the transfer pump in August 1999.

Table 5.2. Base Parameter Values for Buoyancy Model

\begin{tabular}{|c|c|c|c|c|}
\hline Date & 7/19/98 & $9 / 22 / 98$ & $2 / 8 / 99$ & \\
\hline Event & VFI & VFI & RGS & Estimate \\
\hline Crust thickness (cm) & $\mathbf{1 5 0}$ & 155 & 200 & \\
\hline Crust submerged void fraction & 0.3 & 0.32 & 0.34 & \\
\hline Mixed slurry void fraction & 0.013 & 0.015 & 0.025 & \\
\hline Crust freeboard void fraction & 0.34 & 0.34 & 0.34 & 0.34 \\
\hline Crust freeboard porosity & 0.42 & 0.42 & 0.42 & 0.42 \\
\hline Crust freeboard saturation & 0.6 & 0.6 & 0.6 & 0.6 \\
\hline Crust area fraction & 0.86 & 0.86 & 0.86 & 0.86 \\
\hline Degassed level $(\mathrm{cm})$ & 994.5 & 994.5 & 994.5 & 994.5 \\
\hline \multicolumn{5}{|l|}{ Predicted Crust Levels (inches) } \\
\hline Surface & 415.1 & 417.4 & 428.1 & \\
\hline Liquid & 401.7 & 402.9 & 408.7 & \\
\hline \multicolumn{5}{|l|}{ Measured Levels (inches) } \\
\hline Surface & 415.5 & 418.0 & 428.0 & \\
\hline Liquid & 403.0 & 403.4 & 408.0 & \\
\hline
\end{tabular}

(a) Stewart CW. April 1999. Initial Operation Plan for Mechanical Crust Mitigation in Tank 241-SY-101. Letter report TWS99.32, Pacific Northwest National Laboratory, Richland, Washington. 
Table 5.3. Base Crust Configuration (summer 1999)

\begin{tabular}{|l|c|l|c|}
\hline Input Values & & & \\
\hline Bulk slurry void fraction & 0.027 & Degassed level (cm) & 996.5 \\
\hline Freeboard Thickness (cm) & 50 & Freeboard Void Fraction & 0.34 \\
\hline Wet Clay Thickness (cm) & 32 & Wet Clay Void Fraction & 0.08 \\
\hline Paste Thickness (cm) & 203 & Paste Void Fraction & 0.21 \\
\hline Bubble Slurry Thickness (cm) & 25 & Bubble Slurry Void Fraction & 0.60 \\
\hline Total Crust Thickness (cm) & 310 & Avg. Submerged Void Fraction & 0.23 \\
\hline & & Measured Waste Levels (in.) & \\
\hline & & Surface (Enraf 1A) & 431 \\
\hline Computed Values & & Liquid (Enraf 1C) & 412 \\
\hline Submergence (cm) & 260 & Crust Base (in) (Neutron Probe) & 310 \\
\hline Submerged S.G. (including gas) & 1.34 & Predicted Waste Levels (in.) & \\
\hline Freeboard S.G. & 1.98 & Surface & 431 \\
\hline Average crust S.G. & 1.41 & Liquid & 412 \\
\hline Bulk slurry S.G. (including gas) & 1.55 & Crust Base & 310 \\
\hline
\end{tabular}

\subsection{SY-101 Crust Buoyancy Predictions Including Dissolution}

In order to confidently predict the behavior of the crust during back-dilution it is necessary to account for dissolution when applying the crust buoyancy model to the various proposed backdilution scenarios. The following two subsections use the models described in Sections 3 and 4 to investigate the effects of water addition for two general cases. Section 5.3.1 describes the limits when water is added only through injection points low in the tank; Section 5.3.2 describes the limits when some portion of the total water addition is injected on top of the crust.

\subsubsection{Limits on Low Water Addition}

As water is added below the crust, the density of the slurry above the injection point decreases because the slurry is diluted by the added water. This is partially compensated for by the release of gas, which is assumed to be in proportion to the fraction of solids in the slurry that are dissolved. If there is no top dilution, the analysis assumes that the crust is unaffected until all the soluble solids are dissolved from the slurry. At that point, the excess water begins to dissolve the bubble slurry layer. Because the bubble slurry contains a disproportionately high volume of gas, dissolution of this layer will greatly increase the average crust density. When this happens, the diluted slurry will no longer be able to support the heavier crust, and the crust will sink.

In the current plan, two locations will be used for low water addition: the transfer pump inlet, 96 inches from the tank bottom, and the mixer pump burrowing ring, 9 inches from the 
tank bottom. ${ }^{(a)}$ The lower the back-dilution water injection point, the larger the volume of slurry available to mix with the water. This means that the back-dilution volume could be larger if water were added through the mixer pump base rather than through the transfer pump inlet.

For an equal back-dilution volume, larger transfer volumes will result in more dilute slurry. At some point, the resulting mixed slurry density will be too low to float the crust, and the backdilution volume will need to be reduced below the transfer volume to prevent the crust from sinking. With a lower back-dilution volume than transfer volume, the crust base will of necessity be lower because there will be a net decrease in the volume of the mixed liquid slurry as transfer volume is increased. Transfer is finally limited to that volume for which the maximum back-dilution will not raise the crust base sufficiently above the mixer pump inlet to ensure effective operation. Because the mixer pump has operated effectively with the crust base as low as 295 inches, this level has been chosen as the lower limit.

Figure 5.1 shows the maximum back-dilution volume and crust-base elevation as a function of transfer volume. Different curves are shown for the two cases of water addition through the mixer pump base at 9 inches and the transfer pump inlet at 96 inches. (Note that in neither case is water added on top of the crust.) Assuming an equal back-dilution volume, the maximum transfer volumes allowed to prevent crust sinking for these two cases are

- $90 \mathrm{kgal}$ for the 96 -inch injection point

- $120 \mathrm{kgal}$ for the 9-inch injection point.

Both of these conditions keep the crust base above 295 inches. Higher transfer volumes can be achieved by reducing the back-dilution volume enough to keep the crust from sinking while also keeping the crust base above 295 inches. For the two possible injection points, the maximum transfer volumes and corresponding reduced back-dilution volumes are

- $143 \mathrm{kgal}$ transfer volume, $80 \mathrm{kgal}$ back-dilution volume at the 96 -inch injection point

- $175 \mathrm{kgal}$ transfer volume, $112 \mathrm{kgal}$ back-dilution at the 9-inch injection point.

To ensure that the transfer and back-dilution will not cause the crust to sink, it is advisable to reduce the transfer volume somewhat to provide a safety margin in the back-dilution volume. Applying the buoyancy/dissolution models iteratively shows that, for a 100-kgal transfer, crust sinking is predicted with a back-dilution of $84 \mathrm{kgal}$ injected at 96 inches. Limiting the backdilution to $72.5 \mathrm{kgal}$ for this case, however, will keep the crust base above 295 inches. This provides a safety margin of $11.5 \mathrm{kgal}$. With injection at the 9 -inch elevation, crust sinking is predicted at a back-dilution of $116.5 \mathrm{kgal}$ for a $125-\mathrm{kgal}$ transfer. A safety margin of $13.5 \mathrm{kgal}$ is provided if the back-dilution is limited to $103 \mathrm{kgal}$ for this case.

(a) LMHC Interoffice Memo 79000-99-053, from RE Raymond to the SY-101 Project Group, August 18, 1999. Subject: 241-SY-101 Mixer Pump Inlet Level and SY-101 Mixer Pump Drawing H2-89953. 


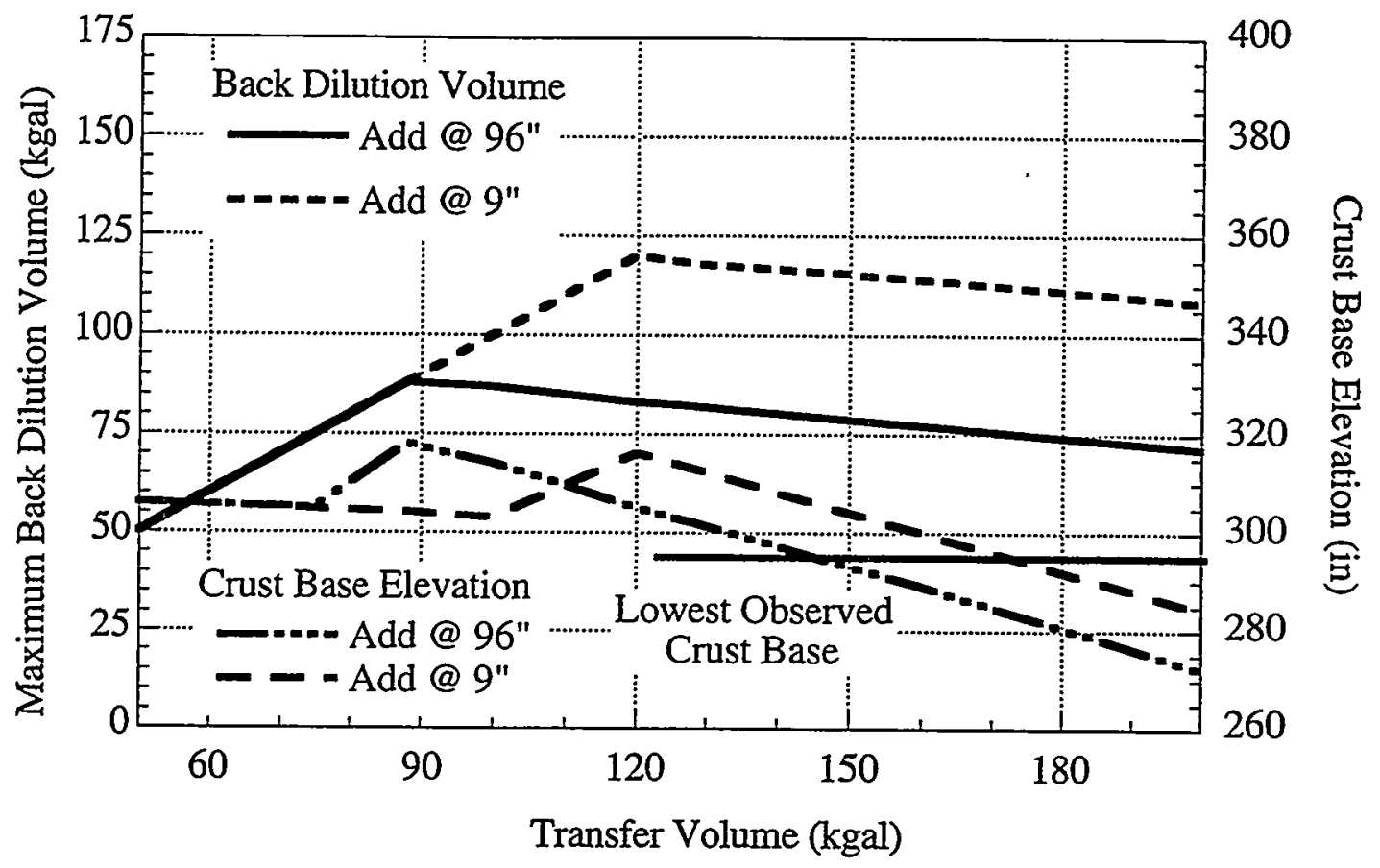

Figure 5.1. Limitation on Low Water Addition to Prevent Crust Sinking

These limits can be further extended by the simple expedient of adding water to the top of the crust to dissolve as much as possible of the heavy freeboard and wet clay layers. These layers are negatively buoyant, so removing them makes the crust much lighter. Within the uncertainty of crust density measurements, dissolving these layers makes the crust positively buoyant almost unconditionally. This is illustrated by repeating the calculations for these two cases with $20 \mathrm{kgal}$ of water added on top of the crust and the remainder of the back-dilution volume injected at each of the two low elevations. The results are shown in Figure 5.2.

The crust base elevation increases initially as the bubble slurry and lower paste layers dissolve, then decreases when back-dilution is limited to prevent crust sinking. For the two injection levels, the maximum transfers with equal back-dilution volumes that will prevent crust sinking are as follows

- $128 \mathrm{kgal}$ for the 96 -inch injection point

- $160 \mathrm{kgal}$ for the 9-inch injection point.

Much larger transfer volumes are possible when the back-dilution volume is reduced to prevent crust sinking. However, with top back-dilution, the crust base remains well above the historic 295-inch minimum for any practicable transfer volume. This result shows that some significant amount of water addition on top of the crust is very beneficial in providing operational flexibility to the transfer and back-dilution process. 


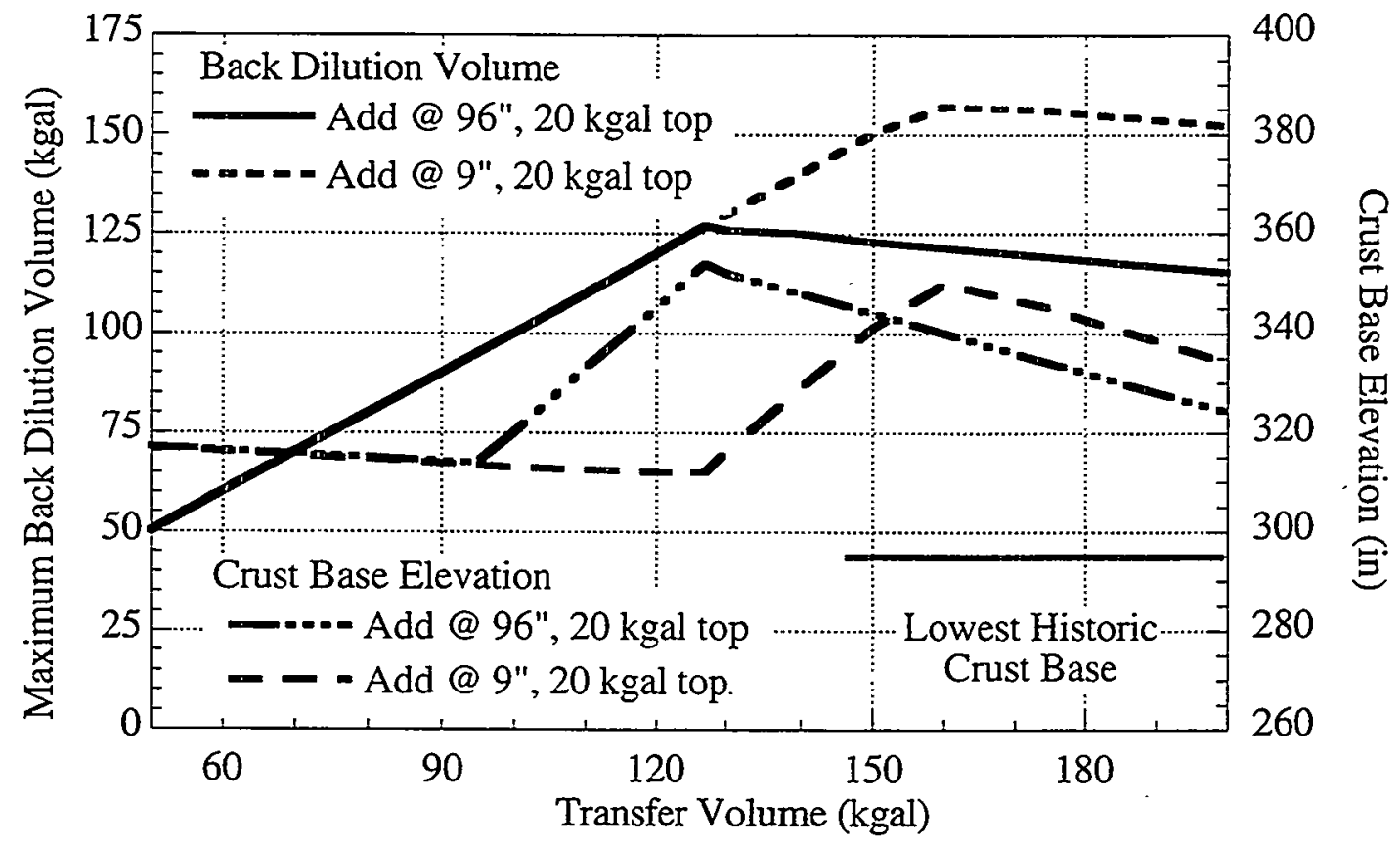

Figure 5.2. Limit on Low Water Addition after $40 \mathrm{kgal}$ Is Added to Crust Top

\subsubsection{Limits on Top Dilution}

With top dilution, crust sinking ceases to be a concern for any transfer or back-dilution volume. As shown by the analyses in Section 5.3.1 above, dissolving the freeboard and wet clay layers removes the negatively buoyant portion of the crust. Dissolution of the paste layer from the top down results in a continuous decrease in the average crust density, which potentially could proceed even to the point where the crust would float in pure water. (The bubble slurry layer by itself has a bulk specific gravity of only 0.7 , with the assumed 0.6 void fraction for this layer of the crust.)

Top dilution raises the crust even more effectively than low addition, although it does not act as immediately. Even before the freeboard dissolves, water placed on top of the crust exerts a significant buoyant force that lifts the crust out of the heavier slurry, as shown by the experimental results presented in Section 3.3 above. As solids in the upper layers dissolve, the density of the fluid mixture on top of the crust increases. When the density of the liquid mixture layer exceeds the bulk density of the crust, the crust can float on it and the mixture flows down to join the slurry. Because of the intimate contact expected between the water and solids, it is estimated that the freeboard layer will completely dissolve within a day. Dissolution of the currently submerged layers will proceed more slowly, and may require on the order of a few weeks.

The only concern that could be considered a limit to top dilution is the potential for the paste layer to be so thinned and weakened that the bubble slurry could penetrate through it. This could release gas from the bubble slurry layer so rapidly that the tank headspace could become flammable. However, transferring waste out and dissolving the upper layers of the crust to the point that the bubble slurry could release gas greatly increases the tank headspace. If all of the bubble 
slurry layer gas were suddenly released after a transfer of $100 \mathrm{kgal}$, the hydrogen concentration would be only slightly above $50 \%$ of the lower flammability limit (LFL). The concentration would be less than $50 \%$ of the LFL following a 150-kgal transfer (assuming that the bubble slurry thickness remains at its present value of approximately 10 inches.)

In addition, it has been demonstrated that a much thinner past layer than presently exists is still strong enough to contain the bubble slurry. During VFI and RGS measurements in the fall of 1998 , a bubble slurry layer existed with a measured void fraction exceeding $50 \%$. The crust at that time was about 60 inches thick, approximately half the current 120 inches. (Note that the crust was only 30-40 inches thick for many years in the past, but it is impossible to determine whether a bubble slurry layer also existed during that time.) This experience shows that the crust can be confidently thinned to at least 60 inches without releasing the bubble slurry.

The predicted effect of top dilution on crust thickness and crust base elevation is shown in Figure 5.3. The figure assumes a 150-kgal transfer, with $30 \mathrm{kgal}$ added at the transfer pump inlet and an additional volume added on top of the crust. The figure shows that about $50 \mathrm{kgal}$ can be placed on top of the crust without reducing the thickness down to the historic 60 inches. Note also that a 35-kgal top addition brings the elevation of the crust base above 295 inches, and further top dilution continues to raise the crust. We conclude that there is no impediment to adding significant volumes of water on top of the crust layer.

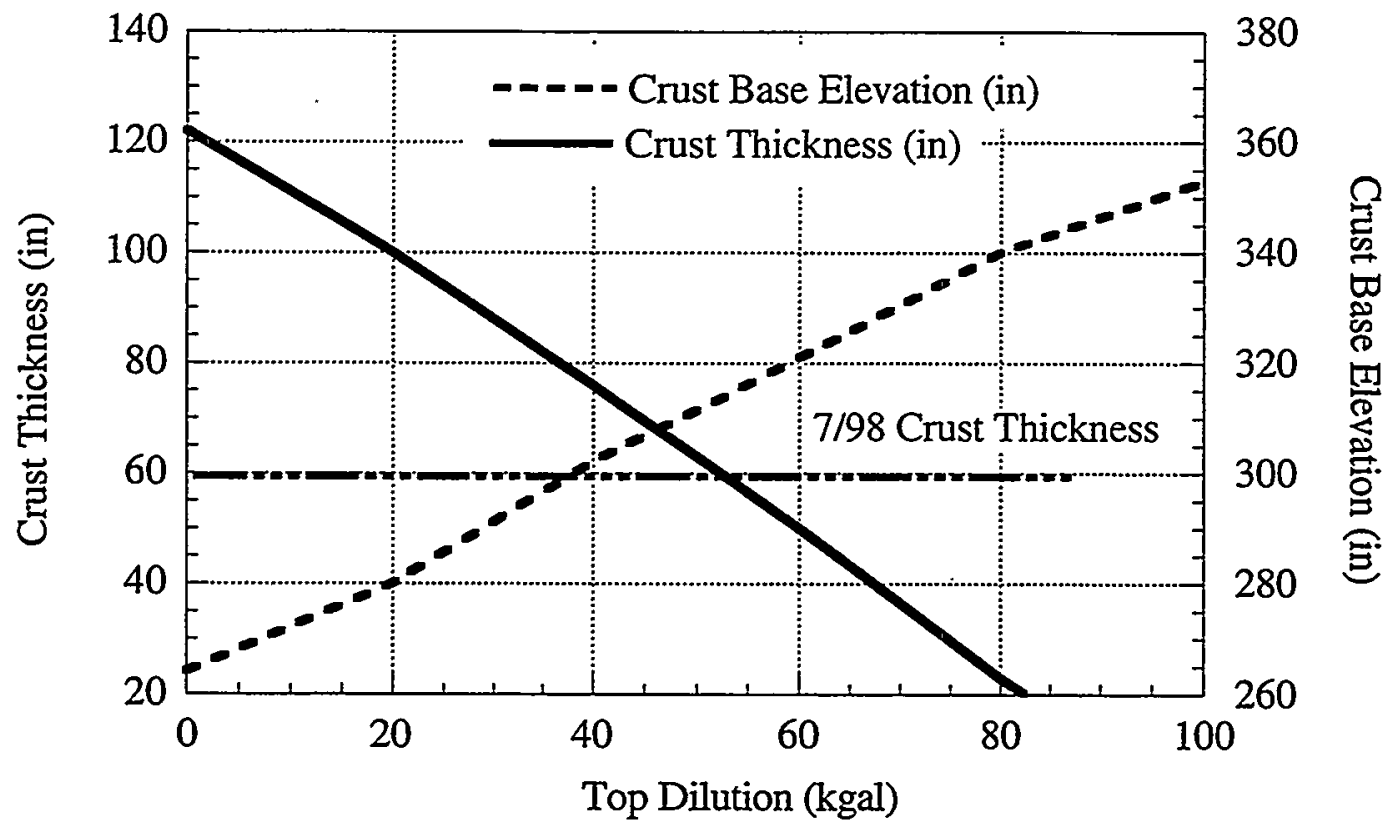

Figure 5.3. Effect of Adding Water to Crust Top after $150 \mathrm{kgal}$ Transfer 


\subsection{References}

Antoniak ZI and PA Meyer. 1999. Potential Waste Stratification from Back-Dilution in Tank 241-SY-101. PNNL-13038, Pacific Northwest National Laboratory, Richland, Washington.

Barton WB. 1999. Maximum First Transfer and Dilution Volume for Tank 241-SY-101. RPP5344, Lockheed Martin Hanford Company, Richland, Washington.

Cussler EL. 1984. Diffusion: Mass Transfer in Fluid Systems. Cambridge University Press.

Herting DL, DB Bechtold, BE Hey, BD Keele, L Jensen, and TL Welsh. 1992. Laboratory Characterization of Samples Taken in December 1991 (Window E) from Hanford Waste Tank 24I-SY-101. WHC-SD-WM-DTR-026, Westinghouse Hanford Company, Richland, Washington.

Mahoney LA, ZI Antoniak, JM Bates, and ME Dahl. 1999. Retained Gas Sampling Results for the Flammable Gas Program. PNNL-13000, Pacific Northwest National Laboratory, Richland, Washington.

Raymond RE. 1999. Tank 241-SY-101 Surface-Level-Rise Remediation Project Plan. HNF-3824 Rev. 0, Lockheed Martin Hanford Corporation, Richland, Washington.

Reynolds DA. 1993. Tank 101-SY Window E Core Sample: Interpretation of Results. WHC-EP-0628, Westinghouse Hanford Company, Richland, Washington.

Schienbein LA, SA Bryan, DL Lessor, PA Meyer and CW Stewart. 1999. Gas Retention and Release Behavior in Hanford Double-Shell Waste Tanks. PNNL-11536 Rev. 2, Pacific Northwest National Laboratory, Richland, Washington.

Stewart CW, JM Alzheimer, G Chen, and PA Meyer. 1998. In Situ Void Fraction and Gas Volume in Hanford Tank 241-SY-101 as Measured with the Void Fraction Instrument.. PNNL-12033, Pacific Northwest National Laboratory, Richland, Washington. 
Appendix

\section{Crust Buoyancy Model}




\section{Appendix}

\section{Crust Buoyancy Model}

The crust buoyancy model uses basic hydrostatics to establish reference conditions from which the effects of dilution are then calculated. This model is illustrated in Figure A.1. Gas is assumed to be retained in the submerged portion of the crust as particle-displacing bubbles of void fraction $\alpha_{c}$. The pores between particles are assumed to be completely saturated with liquid. The overall density of the submerged material is $\rho_{C}$, which depends on the void fraction; the solids volume fraction in the crust, $\phi_{S c}$; and the liquid and solid phase densities, $\rho_{L}$ and $\rho_{S}$, by the expression

$$
\rho_{C}=\left(1-\alpha_{C}\right)\left[\phi_{S C} \rho_{S}+\left(1-\phi_{S C}\right) \rho_{L}\right]
$$

Likewise, the density of the mixed slurry, $\rho_{\mathrm{SL}}$, on which the crust floats depends on the void fraction, solids volume fraction, and phase densities in that layer. It is defined by

$$
\rho_{\mathrm{SL}}=\left(1-\alpha_{\mathrm{SL}}\right)\left[\phi_{\mathrm{SL}} \rho_{\mathrm{S}}+\left(1-\phi_{\mathrm{SL}}\right) \rho_{\mathrm{L}}\right]
$$

All pores and void spaces in the exposed freeboard portion of the crust are assumed open to the headspace and therefore contain the headspace atmosphere. The exposed crust contains void spaces of volume fraction $\alpha_{D}$, which may or may not be equal to $\alpha_{C}$. The solid crust material surrounding the void spaces has porosity $\omega_{\mathrm{D}}$. The pore spaces, but not the voids, are partially filled with liquid at an average saturation of $\psi$. The overall density of the exposed crust is $\rho_{D}$, which is related to the other quantities by

$$
\rho_{D}=\left(1-\alpha_{D}\right)\left[\omega_{D} \psi \rho_{L}+\left(1-\omega_{D}\right) \rho_{S}\right]
$$

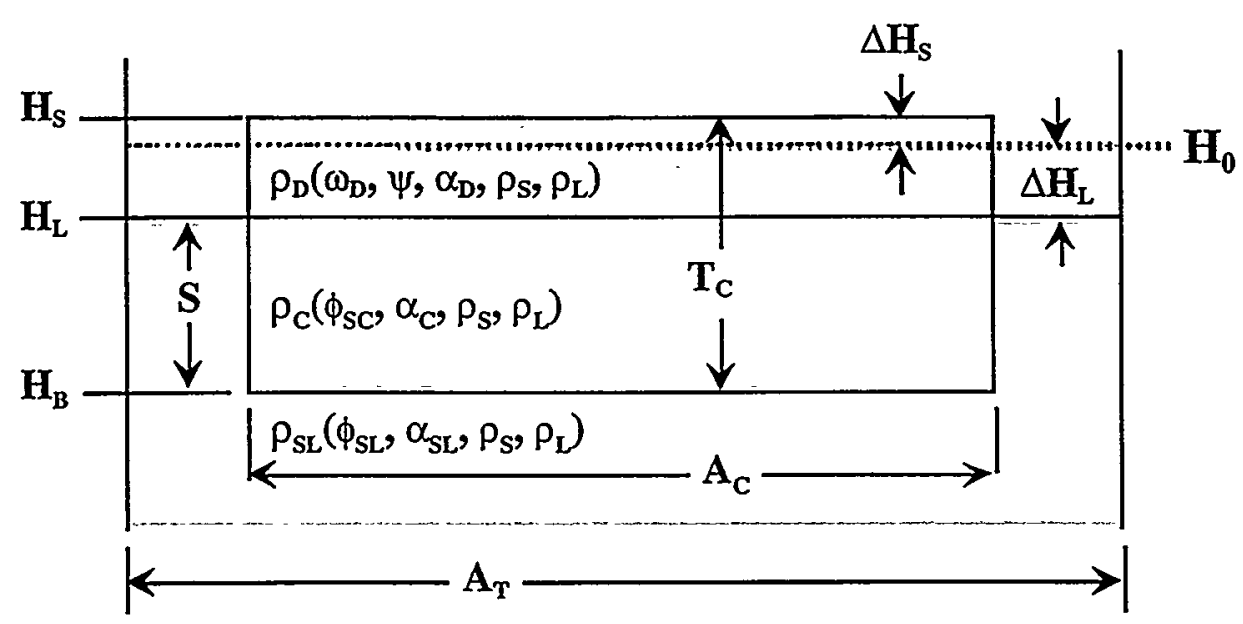

Figure A.1. Detailed Crust Buoyancy Model 
Each of these parameters represents an average estimate over the exposed crust freeboard. While there is considerable uncertainty in determining the open spaces, they must be modeled to accurately represent crust buoyancy and to account for the significant volume of diluent mixture that flows into them. The fraction of the crust freeboard, $\Omega_{D}$, that is open (not liquid or solid) is defined as

$$
\Omega_{D}=\left(1-\alpha_{D}\right) \omega_{D}(1-\psi)+\alpha_{D}
$$

To determine the elevations of the waste surface and free liquid level, we define a reference level, $\mathrm{H}_{0}$, as the height the liquid would attain with the entire crust just submerged. In this hypothetical state, the liquid level matches the crust surface level and the crust thickness is equal to the submergence. The reference level will include the effects of gas retention in the crust as well as in the slurry below it.

As the crust rises a distance $\Delta \mathrm{H}_{\mathrm{S}}$ from the reference state to buoyant equilibrium, the liquid level falls a distance $\Delta \mathrm{H}_{\mathrm{L}}$ to fill in the reduced submerged volume. The excess liquid in the open volume of the portion that will become unsubmerged drains out, which slightly decreases the fall in liquid level. We wish to find an expression $\Delta \mathrm{H}_{\mathrm{L}}$ in order to compute the liquid level, crust surface level, and crust base elevation according to

$$
\begin{aligned}
& \mathrm{H}_{\mathrm{L}}=\mathrm{H}_{0}-\Delta \mathrm{H}_{\mathrm{L}} \\
& \mathrm{H}_{\mathrm{S}}=\mathrm{H}_{\mathrm{L}}+\mathrm{T}_{\mathrm{C}}-\mathrm{S} \\
& \mathrm{H}_{\mathrm{B}}=\mathrm{H}_{\mathrm{L}}-\mathrm{S}
\end{aligned}
$$

The solution for $\Delta \mathrm{H}_{\mathrm{L}}$ is based on conservation of liquid mass for the process of going from the reference state to buoyant equilibrium. This is expressed as

$$
\Delta \mathrm{H}_{\mathrm{L}}\left(\mathrm{A}_{\mathrm{T}}-\mathrm{A}_{\mathrm{C}}\right)=\mathrm{A}_{\mathrm{C}} \Delta \mathrm{H}_{\mathrm{S}}-\mathrm{A}_{\mathrm{C}}\left(\Delta \mathrm{H}_{\mathrm{S}}+\Delta \mathrm{H}_{\mathrm{L}}\right) \Omega_{\mathrm{D}}
$$

where $A_{T}$ and $A_{C}$ are the tank and crust cross-sectional areas, respectively. The crust area is unknown but must be less than the tank area. It is most convenient to include the areas as a ratio, $A_{C} / A_{T}$. Rearranging and applying the identity $\Delta H_{S}=T_{C}-S-\Delta H_{L}$, Eq. (A.1.6) becomes

$$
\Delta H_{L}=\frac{A_{C}}{A_{T}}\left(T_{C}-S\right)\left(1-\Omega_{D}\right)
$$

If we apply Archimedes' principle, the total weight of the crust must equal the weight of slurry it displaces. The weight per unit area of both the exposed and submerged portions of the crust need to be included separately:

$$
S \rho_{C}+\left(T_{C}-S\right) \rho_{D}=S \rho_{S L}
$$

where the densities are defined by Eq. (A.1.1), (A.1.2), and (A.1.3).

Solving for the submergence yields 


$$
S=T_{C} \frac{\rho_{D}}{\rho_{D}+\rho_{S L}-\rho_{C}}
$$

The reference level includes the in situ volume of gas retained both in the crust and in the layers below the crust:

$$
\mathrm{H}_{0}=\mathrm{h}_{0}+\frac{\mathrm{V}_{\mathrm{GSL}}}{\mathrm{A}_{\mathrm{T}}}+\frac{\mathrm{V}_{\mathrm{GC}}}{\mathrm{A}_{\mathrm{T}}}
$$

where $h_{0}$ is the degassed waste level with all solids submerged, $V_{G S L}$ is the in situ gas volume in the slurry layer below the crust, and $\mathrm{V}_{\mathrm{GC}}$ is the in situ gas volume in the crust. Because the crust is assumed submerged at the reference level, the effect of gas in the crust must be distributed over the entire surface area. The volume of gas in the crust can be expressed in terms of the submergence and void fraction as

$$
\mathrm{V}_{\mathrm{GC}}=\alpha_{\mathrm{C}} \mathrm{SA}_{\mathrm{C}}
$$

The gas in the slurry layer can be similarly computed by assigning a void fraction, $\alpha_{\mathrm{SL}}$, for which the non-gas volume is the total degassed volume less the degassed volume of the crust. The result is

$$
\mathrm{V}_{\mathrm{GSL}}=\frac{\alpha_{\mathrm{SL}}}{1-\alpha_{\mathrm{SL}}}\left[\mathrm{h}_{0} \mathrm{~A}_{\mathrm{T}}-\left(1-\alpha_{\mathrm{C}}\right) \mathrm{SA}_{\mathrm{C}}-\left(1-\Omega_{\mathrm{D}}\right)\left(\mathrm{T}_{\mathrm{C}}-\mathrm{S}\right) \mathrm{A}_{\mathrm{C}}\right]
$$

Combining Eq. (A.1.10), (A.1.11), and (A.1.12) provides the final expression for the reference level:

$$
\mathrm{H}_{0}=\mathrm{h}_{0}+\alpha_{C} \mathrm{~S} \frac{\mathrm{A}_{\mathrm{C}}}{\mathrm{A}_{\mathrm{T}}}+\frac{\alpha_{\mathrm{SL}}}{1-\alpha_{\mathrm{SL}}}\left[\mathrm{h}_{0}-\left(1-\alpha_{\mathrm{C}}\right) \mathrm{S} \frac{\mathrm{A}_{\mathrm{C}}}{\mathrm{A}_{\mathrm{T}}}-\left(1-\Omega_{\mathrm{D}}\right)\left(\mathrm{T}_{\mathrm{C}}-\mathrm{S}\right) \frac{\mathrm{A}_{\mathrm{C}}}{\mathrm{A}_{\mathrm{T}}}\right]
$$

The steps required to determine the free liquid level, waste surface level, and crust base elevation are as follows:

1. Determine the submergence with Eq. (A.1.9)

1. Find $\Delta \mathrm{H}_{\mathrm{L}}$ using Eq. (A.1.7)

3. Calculate the reference level, $\mathrm{H}_{0}$, with Eq. (A.1.13)

4. Compute $\mathrm{H}_{\mathrm{L}}, \mathrm{H}_{\mathrm{S}}$ and $\mathrm{H}_{\mathrm{B}}$ via Eq. (A.1.5a), (A.1.5b), and (A.1.5c), respectively.

\section{A.1 Partial Submergence or Flotation}

Figure A.2 is a sketch of the condition before and after a small volume of dilution water is added to the top of the crust or a light diluent mixture percolates to the top of the crust. We assume that no dissolution occurs and that the diluent does not replace the liquid initially occupying the pores. Thus the crust thickness, $\mathrm{T}_{\mathrm{C}}$, and the density and void fraction of the 


\section{INITIAL STATE $\quad$ DILUENT ADDED}

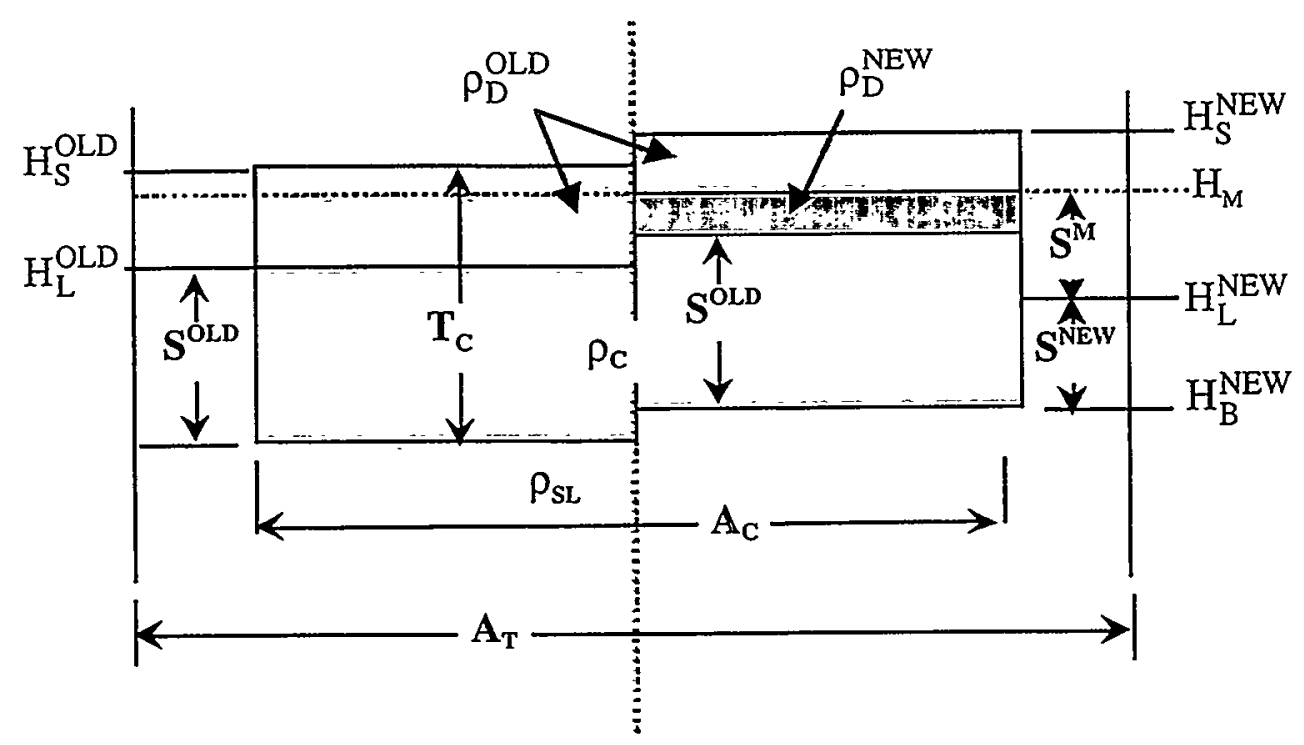

Figure A.2. Small Volume of Diluent Added on Top of the Crust

originally submerged portion of the crust, $\rho_{C}$ and $\alpha_{C}$, respectively, do not change. The density, $\rho_{\mathrm{D}}^{\mathrm{OLD}}$, of the originally unsubmerged portion remaining above the level of the diluent mixture, $\mathrm{H}_{\mathrm{M}}$, are also unchanged. But water can penetrate the pores and voids occupied by air in the original freeboard. Any diluent mixture penetrating the voids and pore space below the water level increases the density in that area to $\rho_{\mathrm{D}}^{\mathrm{NEW}}$. The buoyancy due to the added water increases the difference between the waste surface level, $\mathrm{H}_{\mathrm{S}}^{\mathrm{NEW}}$, and the liquid (salt solution) level, $\mathrm{H}_{\mathrm{L}}^{\mathrm{NEW}}$. This section presents the derivation of expressions for the new waste, liquid, and water levels.

The density of the unfilled portion of the original freeboard, $\rho_{D}^{O L D}$, is given by Eq. (A.1.3). The density of the filled portion, $\rho_{\mathrm{D}}^{\mathrm{NEW}}$, and the density of the diluent mixture, $\rho_{\mathrm{M}}$, are given, respectively, by

$$
\begin{aligned}
& \rho_{D}^{N E W}=\rho_{D}^{O L D}+\Omega_{D} \rho_{M} \\
& \rho_{M}=\frac{\rho_{W}+M \rho_{S L}}{1+M}
\end{aligned}
$$

where $\Omega_{\mathrm{D}}$ is given by Eq. (A.1.4) and $\rho_{\mathrm{SL}}$ by Eq. (A.1.2). The water density is $\rho_{\mathrm{W}}$, and the mixing ratio, $M$, is defined as the ratio of the volume of slurry mixed to the volume of water added. For pure water, $M=0$. Eq. (A.2.1b) assumes either no dissolution or that volume is conserved during dissolution. 
Archimedes' principle for the new condition, equating the weight of the crust with water added to the weight of both displaced water and salt solution, can be stated as

$$
\begin{aligned}
S^{\mathrm{OLD}} \rho_{C}+\left(S^{N E W}+S^{M}-S^{\mathrm{OLD}}\right) \rho_{D}^{N E W}+\left(T_{C}-S^{M}\right. & \left.-S^{N E W}\right) \rho_{D}^{O L D} \\
& =S^{N E W} \rho_{S L}+S^{M} \rho_{M}
\end{aligned}
$$

Solving Eq. (A.2.2) for the difference $\left(\mathrm{S}^{\mathrm{NEW}}-\mathrm{S}^{\mathrm{OLD}}\right)$ gives the following expression:

$$
S^{N E W}-S^{O L D}=\frac{S^{M}\left(\rho_{D}^{N E W}-\rho_{D}^{O L D}-\rho_{M}\right)+S^{O L D}\left(\rho_{C}-\rho_{S L}-\rho_{D}^{O L D}\right)+T_{C} \rho_{D}^{O L D}}{\rho_{S L}-\rho_{D}^{N E W}+\rho_{D}^{O L D}}
$$

Substituting Eq. (A.1.9) for $S^{\mathrm{OLD}}$ and Eq. (A.2.1a) for $\rho_{\mathrm{D}}^{\mathrm{NEW}}$ in Eq. (A.2.3) gives

$$
S^{N E W}-S^{O L D}=-\frac{S^{M} \rho_{M}\left(1-\Omega_{D}\right)}{\rho_{S L}-\rho_{M} \Omega_{D}}
$$

The depth of crust submerged in water, $S^{M}$, can be calculated from the volume of diluent added, $\mathrm{V}_{\mathrm{M}}$, via continuity, assuming the water fills the available air space in the pores and voids above the original liquid level plus the space not occupied by crust (see Figure A.2).

$$
V_{M}=A_{C}\left[S^{M}+S^{N E W}-S^{O L D}\right] \Omega_{D}+S^{M}\left(A_{T}-A_{C}\right)
$$

The mixture volume can also be found by using the definition of the mixing ratio and noting that

$$
\mathrm{V}_{\mathrm{M}}=\mathrm{V}_{\mathrm{SL}}+\mathrm{V}_{\mathrm{W}}=(1+\mathrm{M}) \mathrm{V}_{\mathrm{W}}
$$

Solving Eq. (A.2.5a) for $S^{\mathrm{M}}$ and substituting Eq. (A.2.4) for $S^{\mathrm{NEW}}-\mathrm{S}^{\mathrm{OLD}}$ gives

$$
S^{M}=\frac{V_{M}}{A_{T}}\left[1-\frac{A_{C}}{A_{T}} \frac{\left(1-\Omega_{D}\right)}{\left(1-\frac{\rho_{M}}{\rho_{S L}} \Omega_{D}\right)}\right]^{-1}
$$

With $\mathrm{V}_{\mathrm{M}}$ calculated from the back-dilution volume and the assumed mixing ratio via Eq. (A.2.5b), $S^{M}$ can be calculated with Eq. (A.2.6) and ( $S^{\mathrm{NEW}}-\mathrm{S}^{\mathrm{OLD}}$ ) from Eq. (A.2.4). The new saturated salt liquid level is then calculated from conservation of liquid volume, which is expressed as

$$
\mathrm{H}_{\mathrm{L}}^{\mathrm{OLD}} \mathrm{A}_{\mathrm{T}}-\mathrm{S}^{\mathrm{OLD}} \mathrm{A}_{\mathrm{C}}+\mathrm{V}_{\mathrm{W}}=\mathrm{H}_{\mathrm{L}}^{\mathrm{NEW}} \mathrm{A}_{\mathrm{T}}-\mathrm{S}^{\mathrm{NEW}} \mathrm{A}_{\mathrm{C}}+\mathrm{V}_{\mathrm{M}}
$$

Solving Eq. (A.2.7) for $\mathrm{H}_{\mathrm{L}}^{\mathrm{NEW}}$ and substituting Eq. (A.2.5b) for $\mathrm{V}_{\mathrm{M}}$ yields 


$$
H_{\mathrm{L}}^{\mathrm{NEW}}=\mathrm{H}_{\mathrm{L}}^{\mathrm{OLD}}+\left(\mathrm{S}^{\mathrm{NEW}}-\mathrm{S}^{\mathrm{OLD}}\right) \frac{\mathrm{A}_{\mathrm{C}}}{\mathrm{A}_{\mathrm{T}}}-\mathrm{M} \frac{\mathrm{V}_{\mathrm{W}}}{\mathrm{A}_{\mathrm{T}}}
$$

The rest of the waste levels are then determined with the following identities (Figure A.2):

$$
\begin{aligned}
& \mathrm{H}_{\mathrm{S}}^{\mathrm{NEW}}=\mathrm{H}_{\mathrm{L}}^{\mathrm{NEW}}+\mathrm{T}_{\mathrm{C}}-\mathrm{S}^{\mathrm{NEW}} \\
& \mathrm{H}_{\mathrm{B}}^{\mathrm{NEW}}=\mathrm{H}_{\mathrm{L}}^{\mathrm{NEW}}-\mathrm{S}^{\mathrm{NEW}} \\
& \mathrm{H}_{\mathrm{M}}=\mathrm{H}_{\mathrm{L}}^{\mathrm{NEW}}+\mathrm{S}^{\mathrm{M}}
\end{aligned}
$$

This solution is applicable only if the crust is not completely submerged. The volume of mixed diluent, $V_{M}^{0}$, needed to submerge the crust is computed by substituting $T_{C}-S^{N E W}$ for $S_{M}$ in Eq. (A.2.5a) and using Eq. (A.2.4) for $S^{\mathrm{NEW}}-\mathrm{S}^{\mathrm{OLD}}$ to give the following expression:

$$
\frac{V_{M}^{0}}{A_{T}}=\left(T_{C}-S^{O L D}\right)\left\{\left(1-\Omega_{D}\right)\left(1-\frac{A_{C}}{A_{T}}\right)\left(\frac{\rho_{S L}}{\rho_{S L}-\rho_{M}}\right)+\Omega_{D}\right\}
$$

If the volume of water added is greater than $V_{M}^{0} /(1+M)$, the methodology of the next section should be applied.

\section{A.3 Crust Completely Submerged in Diluent}

If the mixed diluent is less dense than the bulk crust material, the diluent mixture will remain above the liquid level such that the crust may be entirely submerged, as illustrated in Figure A.3. In this case, the sum of the crust submergence depths in the original salt solution and in the mixed diluent is equal to the total crust thickness. Diluent will also penetrate the porosity and void space throughout the entire original freeboard. Applying Archimedes' principle to the configuration of Figure A.3, we have

$$
S^{O L D} \rho_{C}+\left(T_{C}-S^{O L D}\right) \rho_{D}^{N E W}=\left(T_{C}-S^{N E W}\right) \rho_{M}+S^{N E W} \rho_{S L}
$$

noting that $S^{M}=T_{C}-S^{N E W}$ when the crust is submerged. Substituting Eq. (A.1.1a) for $\rho_{D}^{N E W}$ and solving Eq. (A.2.11) for $\left(S^{N E W}-S^{O L D}\right)$ gives

$$
S^{N E W}-S^{O L D}=-\left(T_{C}-S^{O L D}\right) \frac{\rho_{M}\left(1-\Omega_{D}\right)}{\rho_{S L}-\rho_{M}}
$$

With $\left(S^{N E W}-S^{\text {OLD }}\right)$ known, the liquid level $H_{L}^{N E W}$ can be calculated with Eq. (A.2.8) and the waste surface (which is now submerged) and crust base levels with Eq. (A.2.9a) and (A.2.9b). The new mixture level is determined from the amount of diluent in excess of that required to submerge the crust determined by Eq. (A.2.10). This can be expressed as 


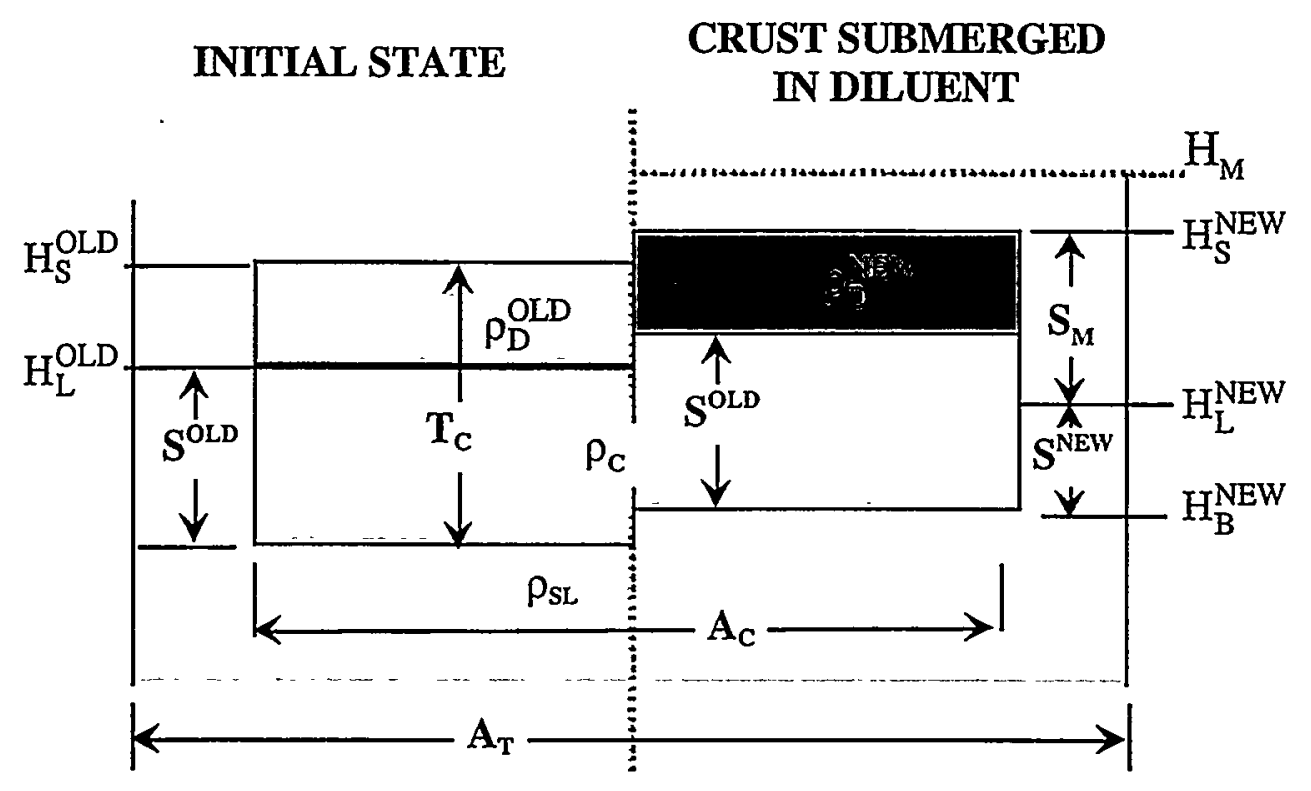

Figure A.3. Diluent Added so Crust Is Completely Submerged

$$
H_{M}=H_{S}^{N E W}+\frac{(1+M)}{A_{T}}\left(V_{W}-V_{W}^{O}\right)
$$

The above model applies only if the diluent density is less than that of the crust. As the mixture density becomes just sufficient to float the crust, the submergence depth in the original salt solution goes to zero. Therefore, to find the diluent mixture density that will float the crust, we set $\mathrm{S}^{\mathrm{NEW}}$ to zero in Eq. (A.2.12) and solve for $\rho_{\mathrm{M}}$ to get the following expression:

$$
\rho_{M}^{0}=\rho_{\mathrm{SL}} \frac{S^{\mathrm{OLD}}}{\left(1-\Omega_{\mathrm{D}}\right) \mathrm{T}_{\mathrm{C}}+\Omega_{\mathrm{D}} \mathrm{S}^{\mathrm{OLD}}}
$$

The required mixing ratio can be found by substituting Eq. (A.2.1b) for $\rho_{M}$ in Eq. (A.2.14) and solving for $\mathrm{M}$.

$$
M^{0}=\frac{1-\frac{\rho_{W}}{\rho_{S L}}\left[\left(1-\Omega_{D}\right) \frac{T_{C}}{S^{O L D}}+\Omega_{D}\right]}{\left(1-\Omega_{D}\right)\left(\frac{T_{C}}{S^{O L D}}-1\right)}
$$

This approach can be used only if $\rho_{M}>\rho_{M}^{0}$.

If $\rho_{M}>\rho_{M}^{0}\left(M>M^{0}\right)$, the crust will float in the diluent mixture without any supporting submergence in the original salt solution and the model in Section A.1 must be used. 


\section{A.3 Crust Floats in Diluent}

If the mixed diluent is more dense than the bulk crust material the crust will float, as illustrated in Figure A.4. This is similar to the base case derived in Section 2 except that the crust will be more deeply submerged because the density will be somewhat less than that of the original slurry. Thus, as in the other two cases, diluent will penetrate the pores and void space in part of the original freeboard. Archimedes' principle for the configuration of Figure A.4 can be stated as

$$
S^{O L D} \rho_{C}+\left(S^{N E W}-S^{O L D}\right) \rho_{D}^{N E W}+\left(T_{C}-S^{N E W}\right) \rho_{D}^{O L D}=S^{N E W} \rho_{M}
$$

Substituting Eq. (A.1.9) for $S^{\mathrm{OLD}}$ and Eq. (A.2.1a) for $\rho_{\mathrm{D}}^{\mathrm{NEW}}$ in Eq. (A.2.16) and solving for $\mathrm{S}^{\mathrm{NEW}}$ yields

$$
S^{N E W}=S^{O L D} \frac{\rho_{S L}-\Omega_{D} \rho_{M}}{\rho_{M}\left(1-\Omega_{D}\right)}
$$

The volume of water needed to just float the crust is the volume of mixed diluent surrounding the crust to a depth of $S^{\text {NEW }}$. Referring to Figure A.3, we find that

$$
V_{M}^{0}=S^{N E W}\left(A_{T}-A_{C}\right)+\left(S^{N E W}-S^{O L D}\right) A_{C} \Omega_{D}
$$

Substituting Eq. (A.2.17) for $S^{\mathrm{NEW}}$ and rearranging yields the following:

$$
\frac{V_{M}^{0}}{A_{T}}=\frac{S^{O L D}}{1-\Omega_{D}}\left\{\frac{\rho_{S L}}{\rho_{M}}\left[1-\left(1-\Omega_{D}\right) \frac{A_{C}}{A_{T}}\right]-\Omega_{D}\right\}
$$

The elevation of the surface of the mixed diluent is determined from conservation of liquid volume before and after dilution. Liquid continuity is expressed as

$$
\mathrm{H}_{\mathrm{L}}^{\mathrm{OLD}} \mathrm{A}_{\mathrm{T}}-\mathrm{S}^{\mathrm{OLD}} \mathrm{A}_{\mathrm{C}}+\mathrm{V}_{\mathrm{W}}=\mathrm{H}_{\mathrm{M}} \mathrm{A}_{\mathrm{T}}-\mathrm{S}^{\mathrm{NEW}} \mathrm{A}_{\mathrm{T}}+\mathrm{V}_{\mathrm{M}}^{0}
$$

Substituting Eq. (A.2.19) for $\mathrm{V}_{M}{ }^{0}$ and solving for $\mathrm{H}_{M}$ gives

$$
\mathrm{H}_{\mathrm{M}}=\mathrm{H}_{\mathrm{L}}^{\mathrm{OLD}}+\mathrm{S}^{\mathrm{NEW}}-\mathrm{S}^{\mathrm{OLD}} \frac{\mathrm{A}_{\mathrm{C}}}{\mathrm{A}_{\mathrm{T}}}+\left[\mathrm{V}_{\mathrm{W}}-(1+\mathrm{M}) \mathrm{V}_{\mathrm{W}}^{0}\right] \frac{1}{\mathrm{~A}_{\mathrm{T}}}
$$

where $\mathrm{V}_{\mathrm{W}}{ }^{0}$ is calculated from $\mathrm{V}_{\mathrm{M}}{ }^{0}$ via Eq. (A.2.5b). The level, $\mathrm{H}_{\mathrm{L}}^{\mathrm{NEW}}$, of the interface between the diluent mixture and the unmixed slurry is found by subtracting the diluent height in excess of that represented by Eq. (A.2.19). Converting the diluent mixture volume to water volume with Eq. (A.2.5b), the expression for $\mathrm{H}_{\mathrm{L}}^{\mathrm{NEW}}$ becomes 


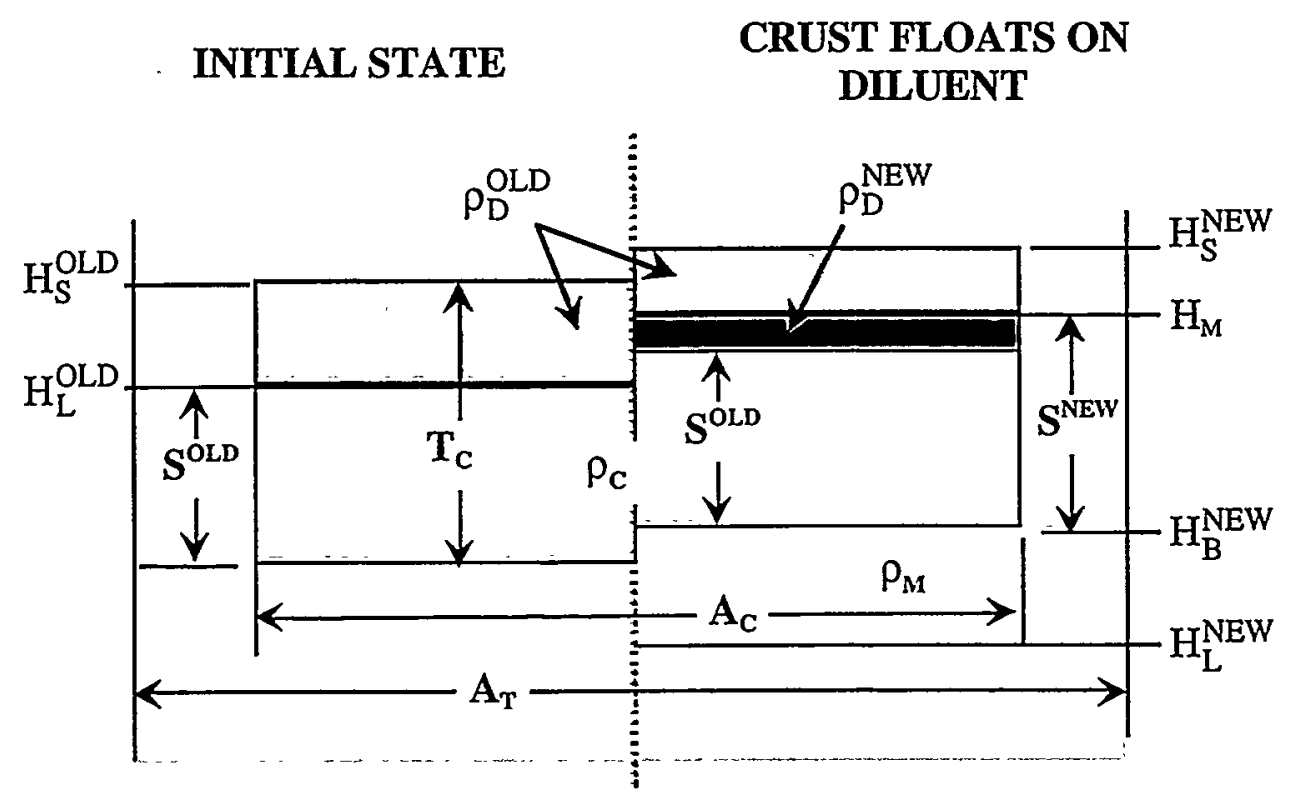

Figure A.4. Diluent Added so Crust Floats on It

$$
\mathrm{H}_{\mathrm{L}}^{\mathrm{NEW}}=\mathrm{H}_{\mathrm{M}}-\mathrm{S}^{\mathrm{NEW}}-\left[\mathrm{V}_{\mathrm{W}}-\mathrm{V}_{\mathrm{W}}^{0}\right] \frac{(1+\mathrm{M})}{\mathrm{A}_{\mathrm{T}}}
$$

With $\mathrm{H}_{\mathrm{M}}$ and $\mathrm{H}_{\mathrm{L}}^{\mathrm{NEW}}$ known, the crust surface and base levels are calculated as follows:

$$
\begin{aligned}
& \mathrm{H}_{\mathrm{S}}^{\mathrm{NEW}}=\mathrm{H}_{\mathrm{M}}+\mathrm{T}_{\mathrm{C}}-\mathrm{S}^{\mathrm{NEW}} \\
& \mathrm{H}_{\mathrm{B}}^{\mathrm{NEW}}=\mathrm{H}_{\mathrm{M}}-\mathrm{S}^{\mathrm{NEW}}
\end{aligned}
$$

This model is valid when the diluent mixture density is greater than that necessary to float the crust. The required density is defined by Eq. (A.2.14), and the mixing ratio is defined by Eq. (A.2.15). 


\section{Distribution}

No. of

Copies

Offsite

2 Office of Scientific and Technical Information

WL Kubic

Los Alamos National Laboratory

PO Box 1663 K575

Los Alamos, NM 87545
No. of

Copies

SD Estey

R2-11

JM Grigsby

R1-44

GD Johnson (3)

S7-73

NW Kirch

R2-11

LJ Kripps

S7-73

CE Leach

R1-44

WJ Powell

S7-70

RE Raymond

S7-70

DA Reynolds

Onsite

19 Pacific Northwest National Laboratory

9 DOE Richland Operations Office

CA Groendyke (6)

H6-60

DH Irby

H6-60

JS Shuen

H6-60

GW Rosenwald

H6-60

16 PHMC Team

WB Barton

R2-11

RE Bauer

S7-73

JR Biggs

S7-07

RJ Cash

S7-73

JM Conner

JM Bates

SQ Bennett

JW Brothers (3)

JM Cuta

WL Kuhn

LA Mahoney

PA Meyer

SD Rassat

CW Stewart (3)

JH Sukamto

Information Release (5)
K7-15

K7-90

K9-20

K7-15

$\mathrm{K} 7-15$

K7-15

K7-15

K6-28

K7-15

K8-93

K1-06

Distr. 1 